\title{
Zusammenfassung und Würdigung
}

Bei seinem Regierungsantritt 1933 übernahm Hitler aus dem Kabinett v. Schleicher den Deutschnationalen Franz Gürtner als Reichsjustizminister, da ihm Gürtners Fachwissen, sein Vertrauen bei der Justizbeamtenschaft und sein während einer langjährigen Ministertätigkeit erwiesener Wille, Forderungen „nationaler“ Politik und Staatsräson in der Justiz zu berücksichtigen, die beste Gewähr für die Verfolgung seiner Ziele zu bieten schienen. Das Präsidialkabinett Hitler entsprach wiederum weitgehend den politischen Vorstellungen Gürtners von einer autoritären, vom Parlament und den Parteien unabhängigen Regierung, die durch die "Nationale Front" von NSDAP, DNVP und Stahlhelm zugleich eine zufriedenstellende Basis im Volk besaß.

Das Gros der deutschen Justizbeamtenschaft - der Richter, Staatsanwälte und Ministerialbeamten - folgte 1933 der Hitler-Regierung schon aus dem Grunde, weil sie „legal“" zur Macht gekommen war und somit in der Kontinuität des Rechts stand. Vor allem das Ermächtigungsgesetz vom 24. März 1933, das die Regierung „durch ein verfassungsänderndes Gesetz vom Parlament im effektiven Besitz der Macht" bestätigte, wirkte sich als eine „Pauschal-Legalisierung“ auch für die zurückliegenden Vorgänge vom Februar und März aus. ${ }^{1}$ Mochte bei der Verabschiedung dieses Gesetzes manches manipuliert worden sein $^{2}$, so wurde es durch die Unterschrift des Reichspräsidenten von ihm als verfassungsmäßig zustandegekommen anerkannt und mit seiner Autorität gedeckt. $^{3}$

Für die Haltung der Justizbeamten gegenüber der Regierung Hitler waren aber nicht nur rechtliche, sondern auch soziale und politisch-ideologische Gründe maßgebend. Da die Nationalsozialisten keine grundsätzliche Veränderung der Eigentumsund Gesellschaftsordnung anstrebten, mußten sie bei der Justiz - die in politischen Angelegenheiten ohnehin „ausgeschaltet“ werden konnte - keine personelle Massensäuberung nach dem Muster der bolschewistischen Revolution vornehmen, um ihre Herrschaft zu sichern. Ein Ersatz der entlassenen Beamten durch linientreue wäre bei dem Mangel an Volljuristen unter den Mitgliedern oder aktiven Anhängern der Partei 1933 auch nicht möglich gewesen. Deshalb sah die überwiegende Mehrheit der Justizbeamten ihre soziale und ökonomische Existenz durch den Nationalsozialismus nicht

1 So Carl Schmitt, Das Problem der Legalität (1950), in: Verfassungsrechtliche Aufsätze aus den Jahren 1924-1954. Materialien zu einer Verfassungslehre, Berlin 1958, S.440ff., 442.

2 Zu den Manipulationen aus rechtlicher Sicht: K. Revermann, Die stufenweise Durchbrechung des Verfassungssystems der Weimarer Republik in den Jahren 1930 bis 1933. Münster 1959, S.116ff., ferner: R. Morsey, Ermächtigungsgesetz (1992).

${ }^{3}$ Schmitt (a.a.O.) behauptet sogar, durch das Ermächtigungsgesetz sei ,jeder legale Weg einer Rückgängigmachung der Machtergreifung verbaut “ worden, und meint - wohl mit Recht -, daß danach eine Entlassung Hitlers und die Ernennung eines neuen Reichskanzlers durch Hindenburg nur zum Preis eines Bürgerkrieges unter Einsatz der Reichswehr zu erreichen gewesen wäre. 
gefährdet. Im Gegenteil kam die von den Nationalsozialisten propagierte „Wiederherstellung des Berufsbeamtentums“ ihren Standesinteressen und ihrer Vorstellung von einem sachlich arbeitenden, ,unpolitischen“ Beamtentum entgegen und ließ sie auch die Entlassung von Beamten hinnehmen, die bislang diese Vorstellung durch die Forderung einer „Republikanisierung“ der Justiz bekämpft hatten ${ }^{4}$ oder ausgesprochene Gegner der Nationalsozialisten gewesen waren. Bei einem Teil von ihnen - gleich, ob sie dem im deutschen Bürgertum latent vorhandenen Antisemitismus anhingen oder nicht - weckte auch die angekündigte Entfernung der Juden aus der Justiz Aussichten auf Beförderungschancen, unter dem großen Heer der auf Anstellung wartenden Assessoren und zahlreichen in wirtschaftlicher Not lebenden Rechtsanwälte Hoffnung auf die Sicherung ihrer materiellen Lebensgrundlage. Die Gefahr, die eine totalitäre Monopolpartei mit ihren Forderungen für das traditionelle Beamtentum darstellen konnte, blieb ihren Augen noch weitgehend verborgen.

Die politische Einstellung der führenden Justizbeamten, die mit wenigen Ausnahmen dem mittleren und gehobenen Bürgertum entstammten und ihre Berufslaufbahn in der Kaiserzeit begonnen hatten, war überwiegend - wie die ihres Ministers - national und konservativ. Auch in der Weimarer Zeit huldigten sie als bloße „Vernunftrepublikaner" dem Ideal eines Staatswesens, das über den Interessen- und Machtkämpfen der politischen Parteien stand und von einem „unpolitischen“ Berufsbeamtentum getragen wurde. ${ }^{5}$ Diese politische Einstellung machte sie für die Parolen der Nationalsozialisten empfänglich und ließ sie mit deren vorgegebenen „nationalen“ Zielen sympathisieren. Obwohl sich viele von ihnen innerlich von den negativen Erscheinungen des Nationalsozialismus distanzierten, begrüßten sie die „nationale Erhebung“, die von der Autorität Hindenburgs gedeckt wurde und eine Beseitigung pluralistischer Einflüsse der verschiedenen, einander bekämpfenden politischen und sozialen Gruppen auf den Staatsapparat versprach und damit ihre Wunschvorstellung vom "Staat" zu verwirklichen schien. Von der „nationalen“ Regierung erhofften sie die Wiederaufrichtung einer autoritären Ordnung, die auch außenpolitisch die Folgen der Niederlage von 1918 zu beseitigen in der Lage war. Diese Affinität zu den vorgegebenen Zielen des Regimes, die auch Reichsjustizminister Gürtner aufwies, führte zur Bereitschaft, sich anzupassen und bei der Mißachtung überlieferter Rechtsprinzipien, die das neue Regime gegenüber politischen Gegnern und „Staatsfeinden“ zeigte, Zugeständnisse zu machen - zumal sie zunächst als eine vorübergehende Erscheinung angesehen wurde, die mit der innenpolitischen Konsolidierung verschwinden würde. Auch die als zeitweilig angesehene Einschränkung der vollen Rechtsstaatlichkeit durch die Reichstagsbrandverordnung diente in ihren Augen dem Schutz des Staates vor linksradikalen Elementen, die - nach dem angeblichen Ermittlungsergebnis durch die politische Polizei anläßlich des Reichstagsbrandes - einen gewaltsamen Umsturz planten und damit schließlich auch die sozialen und politischen Grundlagen der Justizbeamtenschaft bedrohten. Daß die nationalsozialistische Führung hinter der offiziellen Fas-

4 Vgl. dazu R. Kuhn, Die Vertrauenskrise der Justiz (1926-1928). Der Kampf um die „Republikanisierung“ der Rechtspflege in der Weimarer Republik, Köln 1983.

s Zur gedanklichen Trennung von ,zufälliger" Staatsform und dem Wesen des Staates, dem der unpolitische Richter allein verpflichtet sei, in der Weimarer Zeit vgl. F. K. Kübler, Der deutsche Richter und das demokratische Gesetz (Archiv für die civilistische Praxis 1963, S. $104 \mathrm{ff}$.), S. $115 \mathrm{ff}$. 
sade das Ziel verfolgte, den Rechtsstaat für die Aufrechterhaltung ihrer Diktatur und die Durchführung ihrer Ziele für immer zu beseitigen, war zunächst nicht erkennbar.

Die leitenden Beamten im Reichsjustizministerium sahen ihre Machtstellung, die sie in der Endphase der Weimarer Republik zusammen mit der Ministerialbürokratie der anderen Ministerien durch die Verordnungspraxis des Artikels 48 der Reichsverfassung als wesentliche Träger des Präsidialsystems gewonnen hatten - sie waren praktisch zum Gesetzgeber geworden -, durch die neue Regierung nicht gefährdet, da die als Präsidialkabinett eingesetzte Regierung Hitler auf die Dauer ohne Parlament mit Hilfe von Regierungsgesetzen zu arbeiten beabsichtigte. Diese Regierungsgesetze sollten dem Justizministerium im Gegenteil weitgehende Rechtsetzungs- und Verordnungsgewalt delegieren. Statt vom Parlament und seinen Parteien wurde das Justizministerium allerdings nunmehr allein von Hitler als Gesetzgeber abhängig, und es sollte sich herausstellen, daß die einzig verbliebene Partei bei der Gesetzgebung nachhaltig mitreden und ihr nicht genehme Gesetze verhindern konnte.

Ein Aufgabengebiet, auf dem das Reichsjustizministerium nach der Machtübernahme umfassende Befugnisse übertragen bekam, war der Aufbau einer einheitlichen Justizorganisation durch die Überleitung der Justizverwaltung von den Ländern auf das Reich. Hier gingen die Interessen der leitenden Männer des Reichsjustizministeriums mit den Zielen der politischen Führung, die föderalistische Struktur des Reiches zu beseitigen und einen unitarisch organisierten Staat aufzurichten, konform. Die Errichtung eines zentral geleiteten Justizapparats war auch eine wesentliche Voraussetzung, um die von der Führung gestellten Aufgaben in den verschiedenen Tätigkeitsbereichen der Justiz erfüllen zu können: Sie ebnete den Weg für eine einheitliche Personalpolitik beim höheren Dienst und für die nach einheitlichen Gesichtspunkten ausgerichtete Ausbildung, Auslese, Ernennung und Beförderung aller Justizbeamten. Sie ermöglichte eine zentrale Beobachtung der Tätigkeit der Justizbehörden und wurde so die Grundlage für die spätere zentrale „Lenkung“ der Rechtsprechung. Da das Reichsjustizministerium zugleich das verantwortliche Organ für die Vorbereitung von Gesetzen auf dem Justizgebiet war, gestattete diese unmittelbare Verbindung mit der Praxis, gegebenenfalls rasch mit gesetzgeberischen Maßnahmen zu reagieren, um unerwünschte Entwicklungen zu unterbinden.

War die „Verreichlichung“ zugleich eine Maßnahme, um künftig die Justiz den Forderungen der politischen Führung wirksamer anpassen zu können, so hatte jedoch das innere Engagement, mit dem sich die leitenden Männer des Reichsjustizministeriums dieser Aufgabe annahmen, auch Gründe, die mit den Interessen der Partei nicht im Einklang standen. Bedeutete die Zentralisierung doch vor allem die Ablösung der 1933 ernannten nationalsozialistischen Landesjustizchefs, deren radikale Einstellung in verschiedenen Bereichen - etwa bei der „Arisierung“ der Justiz und bei gesetzgeberischen Neuerungen - zur Auseinandersetzung mit dem konservativen und gemäßigteren Reichsjustizministerium geführt hatte. Zudem verringerte die Zuständigkeitsverlagerung auf die Reichsebene die Aussicht der Gauleiter/Reichsstatthalter, auf die Tätigkeit der Justiz unmittelbar und mit Erfolg einwirken zu können: war diese Einflußnahme bisher in letzter Instanz auf die meist nachgiebigen, linientreuen Landesjustizchefs gestoßen, so mußte sie nunmehr - meist sogar erst auf dem Weg über die Parteizentrale - beim Reichsjustizministerium ansetzen, das unberechtigten Forderungen entgegentrat. In diesem Zusammenhang war es z. B. von Bedeutung, daß die 
im Sommer 1933 im preußischen Justizministerium gegründete Zentralstaatsanwaltschaft - die die Ermittlung und die Anklagevertretung vor Gericht in jenen „heiklen“ Strafverfahren an sich ziehen konnte, in die Funktionäre und Angehörige der Bewegung verwickelt waren, und die von den Gauleitern oder Parteistellen durch Druck auf die örtlichen Justizorgane zu unterbinden oder zu beeinflussen gesucht wurden - nunmehr im ganzen Reich tätig werden konnte.

Die Vorteile, die sich das Reichsjustizministerium von der Verreichlichung der Justiz gegenüber der Partei erhoffte, wären hinfällig geworden, wenn die Aufgabe der organisatorischen Vereinheitlichung des Justizapparats in parteihörige Hände übergegangen wäre. Deshalb war es ein wesentlicher Erfolg Gürtners und Schlegelbergers, daß sie derartige Ansprüche von seiten der beiden wichtigsten, miteinander aber rivalisierenden NS-Juristen abwenden konnten: Der 1933 zum „Reichskommissar für die Gleichschaltung der Justiz in den Ländern" bestellte Leiter der Rechtsabteilung der NSDAP und Führer des BNSDJ, Hans Frank, konnte auf die Aufgabe beschränkt werden, die juristischen Berufsverbände und Standesvereinigungen einheitlich auszurichten und in seiner Juristenorganisation zusammenzufassen. Die Versuche des 1933 zum preußischen Justizminister ernannten Hanns Kerrl, sein Ministerium - dem ohnehin schon der überwiegende Anteil der deutschen Justizbehörden unterstand - zum Reichsjustizministerium zu machen und Gürtners Ministerium zu einem Reichsgesetzgebungsministerium umzuwandeln, konnten vereitelt werden und beschleunigten nur die Vereinigung des Reichs- mit dem Preußischen Justizministerium unter Gürtner. Die erfolgreiche Behauptung des Reichsjustizministeriums gegenüber den Ansprüchen von Parteijuristen auf Übernahme der „Verreichlichung“ war allerdings nur durch Hitlers Rückendeckung möglich, der Gürtner wegen seiner Autorität bei den Justizbeamten und seiner größeren ministeriellen Erfahrung gegenüber Frank vorzog, gegen Kerrls Absicht einer bloßen Ausdehnung der preußischen Justizverwaltung auf die anderen Länder des Reichs süddeutsche Ressentiments befürchtete und diese Aufgabe daher beim langjährigen bayerischen Justizminister am besten aufgehoben sah. In der Tat nahm Gürtner auf die Gefühle und Traditionen der nichtpreußischen Länder weitgehend Rücksicht, vermied jeden überspannten Zentralismus und fand 1934 in der Bildung der drei nord-, mittel- und süddeutschen Arbeitsgemeinschaften einen Weg, auf dem bewährte landesrechtliche Regelungen in das neue einheitliche Justizverwaltungsrecht übernommen werden konnten. Den am 1. April 1935 abgeschlossenen Aufbau der Reichsjustiz als einer wichtigen „Säule des deutschen Einheitsstaates“, in die auch die Justiz des kurz vorher rückgegliederten Saarlandes eingebaut war, hatte Gürtner mit solcher Umsicht durchgeführt, daß sie bei der Justizbeamtenschaft im Reich überwiegende Zustimmung fand.

Auf dem Gebiet der Personalpolitik räumte das Reichsjustizministerium der Partei ein Mitspracherecht ein und konnte folglich seine eigenen Vorstellungen nicht immer durchsetzen. Obwohl die Frage der „arischen“ Abstammung bei der Stellenbesetzung im eigenen Hause bis zur „Machtübernahme“ keine Rolle gespielt hatte, beugte sich das Ministerium widerstandslos der nationalsozialistischen Forderung nach „Arisierung" der Justiz, setzte sich jedoch nachdrücklich dafür ein, daß in die beiden Gesetze für Berufsbeamte und Rechtsanwälte vom April 1933 die auch von Hindenburg geforderten Ausnahmen zugunsten jüdischer Frontkämpfer, „Altbeamter“, „Altanwälte“ usw. aufgenommen wurden. Durch diese Abschwächung der „Säuberungs“-Maß- 
nahme geriet das Reichsjustizministerium in eine Auseinandersetzung mit den Landesjustizchefs, die bis zur „Verreichlichung“ für die Personalpolitik in ihren Ländern zuständig blieben und im März 1933 noch vor einer gesetzlichen Regelung alle jüdischen Richter und Staatsanwälte beurlaubt und den jüdischen Rechtsanwälten ein Vertretungsverbot vor Gericht erteilt hatten mit der festen Absicht, sie für immer von der Ausübung ihres Amtes bzw. Berufs auszuschließen. Als das Reichsjustizministerium trotz des Protestes der Landesjustizchefs die erwähnten Ausnahmen auch für Rechtsanwälte durchsetzte, versuchten sie, die strikte Durchführung der Gesetze durch eigenmächtige Auslegung zu sabotieren, um ihre radikalen Maßnahmen nicht zurücknehmen zu müssen, und konnten vom Reichsjustizministerium nur durch den Erlaß genauer Durchführungsverordnungen auf Reichsebene daran gehindert werden. Dabei kam dem Ministerium zustatten, daß Hitler auf die Gefühle nationalkonservativer Kreise und auf die Reaktion im Ausland noch Rücksicht nehmen und vorläufig von allzu radikalen antisemitischen Maßnahmen absehen mußte.

Die gesetzlich vorgesehene Entfernung von Juristen wegen ihrer politischen Vergangenheit stieß bei der leitenden Ministerialbürokratie aus der erwähnten Einstellung heraus auf mehr innere Zustimmung als die „Arisierung“. Daß das Reichsjustizministerium im eigenen Haus keinen einzigen Beamten vom Oberregierungsrat aufwärts aus politischen Gründen entlassen mußte, zeigt die - nicht zuletzt auch fachlich begründete - homogene nationalkonservative Zusammensetzung, die es sich während der Weimarer Zeit bewahrt hatte. Demgegenüber offenbart die Tatsache, daß Gürtner und Schlegelberger trotz der gegenteiligen Bestrebungen Freislers - der seit der Vereinigung mit dem Preußischen Justizministerium 1934 als zweiter Staatssekretär die Interessen der Partei im Ministerium vertrat - jüdische „Mischlinge“, darunter bis 1936 einen „halbjüdischen“ Abteilungsleiter, im Amt behielten, wie wenig rassistisches Gedankengut ins Justizministerium Eingang gefunden hatte. Auch als im November 1935 nach Erlaß des Reichsbürgergesetzes die bisherigen Ausnahmen zugunsten jüdischer Beamter wegfielen und alle Ministerialbeamten den Ariernachweis für sich und ihre Ehefrau erbringen sollten, wurde die Aktion im Reichsjustizministerium hinhaltend durchgeführt; „zweifelhafte“ Fälle wurden auf Gürtners Weisung hin möglichst diskret behandelt. Der immer drängender werdenden Forderung der Partei und des NS-Rechtswahrerbundes nach Ausschaltung der noch als Ausnahmen zugelassenen jüdischen Rechtsanwälte gab das Reichsjustizministerium 1938 erst nach, nachdem deren Mindestversorgung und die Vertretung der Juden vor Gericht durch die Zulassung jüdischer „Konsulenten“ erreicht waren.

Die homogene politische Zusammensetzung des Reichsjustizministeriums änderte sich im Oktober 1934 durch die Vereinigung mit dem Preußischen Justizministerium, in das dank Kerrl und Freisler auch aktive Nationalsozialisten Eingang gefunden hatten. Durch die Vergrößerung des Personalbestandes, die sich aus der Übernahme der Geschäfte der Landesjustizverwaltungen nach 1935 ergab, und die dabei vorgeschriebene Mitwirkung der Partei stieg der Anteil der Parteigenossen im Ministerium in den folgenden Jahren an. Jüngere Nachwuchskräfte waren meist schon aufgrund der neuen Ausbildungs- und Anstellungsvorschriften in die Partei eingetreten; aber auch langjährig bewährte Kräfte, die in leitenden Vertrauensstellungen gehalten oder dorthin befördert werden sollten, mußten nunmehr ihren Weg in die Partei finden. Ende 1938 gehörten schließlich knapp die Hälfte der Beamten des Reichsjustizministeriums der 
NSDAP an, darunter zwei der sechs Abteilungsleiter. Wenngleich nur ein kleiner Teil dieser nach der "Machtübernahme“ in die Partei Eingetretenen zu überzeugten Nationalsozialisten wurde, zeigt sich darin doch, bis zu welchem Grad sich die Ministerialbeamtenschaft dem Regime anpaßte. Blieb während Gürtners Amtszeit die fachliche Qualifikation und nicht die Parteimitgliedschaft das entscheidende Kriterium für die Ernennung und Beförderung im Ministerium, so wirkte sich allein die allmähliche Besetzung weniger Schlüsselstellungen - etwa in der Freisler unterstehenden politischen Strafrechtspflege - dahingehend aus, daß das Ministerium im Sinne der politischen Führung reibungsloser arbeitete.

Die Einflußnahme der Gauleiter auf die Besetzung der regionalen Justizbehörden konnte das Reichsjustizministerium durch die „Verreichlichung“ der Justiz nicht abschaffen: der zuständige Gauleiter blieb bis Oktober 1940 auch bei der Ernennung von Beamten des höheren Dienstes - also der Richter und Staatsanwälte - vorgeschaltet, die durch Hitler erfolgte und für die die Vorschläge vom Ministerium im Einvernehmen mit dem Stellvertreter des Führers eingereicht wurden. Immerhin vermochte das Ministerium nach der „Verreichlichung“ den Widerstand der Gauleiter gegen Personalvorschläge häufig durch Verhandlungen mit dem Stellvertreter des Führers auf oberster Ebene auszuräumen, mußte sich allerdings in manchen Fällen auch auf Kompromißkandidaten einigen. Soweit sich die Gauleiter nicht auf die politische Beurteilung der vorgeschlagenen Bewerber beschränkten, sondern von sich aus Beamte vorschlugen und deren Ernennung durchzusetzen suchten, konnte sich das Ministerium - wie zumindest bei den Spitzenstellen nachweisbar - dieser meist fachlich nicht geeigneten Kandidaten mit Erfolg erwehren. Es konnte sich dabei auf Hitlers grundsätzliche Entscheidung berufen, daß das Vorschlagsrecht allein beim Ressortminister liege, der die Verantwortung für seine Verwaltung zu tragen habe. Der Einfluß, den die einzelnen Gauleiter auf die Personalpolitik der Oberlandesgerichtspräsidenten und Generalstaatsanwälte in ihren Gauen ausübten, die für die Ernennung und Beförderung der mittleren und unteren Beamten ihres Bezirks zuständig waren, dürfte unterschiedlich intensiv gewesen sein. Das Reichsjustizministerium wurde hier nur bei unüberbrückbaren Gegensätzen eingeschaltet und vertrat dann meist den Standpunkt der Behördenchefs gegenüber der Partei. Als Fazit bleibt festzustellen, daß das Reichsjustizministerium seine weiterhin fachlich orientierte Personalpolitik in der Justizverwaltung nicht mehr allein bestimmen konnte, sondern zu Zugeständnissen an die Partei gezwungen war.

Anders als beim Aprilgesetz über die „Säuberung“ der Rechtsanwaltschaft, dessen Durchführung im Interesse der Rechtssicherheit für die verbliebenen jüdischen Anwälte im Herbst 1933 für abgeschlossen erklärt werden konnte, gelang es dem Reichsjustizministerium trotz mehrfacher Bemühungen nicht, im Interesse der Wiederherstellung der persönlichen Unabhängigkeit der Richter ein Gleiches für das ursprünglich zeitlich begrenzte, aber mehrmals verlängerte Berufsbeamtengesetz zu erreichen. Da auch im Deutschen Beamtengesetz vom Januar 1937 auf Wunsch der politischen Führung die Pensionierung eines Beamten wegen politischer Unzuverlässigkeit vorgesehen wurde ( $(71)$, setzte das Reichsjustizministerium wenigstens die Aufnahme einer Bestimmung durch, daß die Zwangspensionierung eines Richters nicht auf ein von ihm gefälltes Urteil gestützt werden durfte (§ 171), ferner daß das für diese Pensionierungsfälle eingerichtete Untersuchungsverfahren in seiner eigenen Zuständigkeit 
blieb. Durch äußerst geschicktes Verhalten gelang es Gürtner 1938, Hitlers Forderung abzuwenden, die rechtlichen Garantien der persönlichen Unabhängigkeit des Richters, die der Partei ein Dorn im Auge waren, vollends abzuschaffen und außer einer Absetzung des Richters auch seine - demgegenüber leichter durchführbare - Zwangsversetzung ${ }^{6}$ wegen einer von ihm gefällten richterlichen Entscheidung - also nicht aus dienststrafrechtlichen Gründen - gesetzlich vorzusehen. Nur widerwillig verzichtete Hitler auf eine Änderung der gesetzlichen Bestimmungen und erklärte sich schließlich bereit, daß die Reichskanzlei lediglich in einem vertraulichen Rundschreiben vom Juli 1938 alle Reichsminister, in deren Ressort es Gerichte gab, von Hitlers Auffassung unterrichtete, daß auch eine gerichtliche Entscheidung zum Anlaß genommen werden könne, um einen Richter nach $\S 71$ des Beamtengesetzes in den Ruhestand zu versetzen. Bezeichnenderweise findet sich jedoch unter den sechs Verfahren, die in der Amtszeit Gürtners aufgrund dieses Paragraphen gegen Richter durchgeführt wurden, nicht ein einziges, bei dem die Rechtsprechung des betreffenden Richters der Anlaß gewesen war. Soweit von der Partei angegriffene Justizbeamte im nationalen Sinn ,in Ordnung" waren, stellte sich das Reichsjustizministerium meist schützend vor sie und lehnte die geforderte Einleitung eines Verfahrens nach $\S 71$ gegen sie ab.

In der Strafrechtspflege kollidierte die Justiz mit den neuen Trägern der Macht 1933 bei der Verfolgung der kriminellen Ausschreitungen von Anhängern der nationalsozialistischen Bewegung gegen ihre politischen Gegner, die vor allem von der als „Hilfspolizei“ eingesetzten SA begangen wurden. Da die meisten dieser Straftaten von der politischen Führung gedeckt wurden, stand die Justiz diesen ungesetzlichen Terrorhandlungen, von denen sie im März an einigen Orten selbst betroffen wurde, ziemlich hilflos gegenüber: die unteren Justizbehörden gerieten bei der pflichtgemäßen Verfolgung dieser Straftaten unter den Druck örtlicher Partei- und SA-Stellen und fanden bei ihren Ermittlungen seitens der von NS-Funktionären durchsetzten Polizei und Verwaltung keine Unterstützung. Im Gegenteil wurden die Ermittlungsverfahren durch Aussageverbote von SA- und SS-Führern an ihre Untergebenen, durch Verbergen der Beschuldigten, Bedrohung von Zeugen mit Schutzhaft, Einbehaltung von Verfahrensakten usw. sabotiert. Da auch über Vizekanzler v. Papen unternommene Vorstöße bei Hitler nichts fruchteten, der in dieser „historischen Stunde“ ein hartes Vorgehen befürwortete, glaubte das Reichsjustizministerium das Problem durch eine von der Reichsregierung am 21. März erlassene Straffreiheitsverordnung lösen zu können: während in der als vorübergehend angesehenen „revolutionären“ Ausnahmesituation die „im Kampfe für die nationale Erhebung“ begangenen Straftaten durch Einstellung der Verfahren und Straferlasse amnestiert wurden, sollte nach diesem Datum das Strafrecht wieder gegenüber jedermann durchgesetzt werden. Als aber die ungesetzlichen Handlungen der SA selbst noch andauerten, nachdem Hitler und Frick im Juli 1933 durch wiederholte Verlautbarungen die „Revolution“ für beendet erklärt hatten, sahen die Landesjustizchefs - die für die Durchführung der Straffreiheitsverordnung vom März zuständig waren - Verfahren vor und erließen Bestimmungen, um die einschlägigen Straftaten prüfen und in Einzelfällen aus „staatspolitischen Gründen“ Niederschlagungen und Begnadigungen anordnen zu können. Es gelang ihnen aber

6 Über die realisierten rechtlichen Handhaben für die Versetzung von Richtern, insbesondere das GeschäftsverteilungsG v. 24.11.37 und die Vereinfachungsmaßnahmen im Kriege vgl. Kapitel III.1.c., S. 196, und Kapitel VIII.1.b., S. 973 ff. 
nicht, die Entscheidung darüber de facto in ihrer eigenen Zuständigkeit zu halten: über diese Strafverfolgungsfälle kam es zu ständigen Auseinandersetzungen zwischen den Justizbehörden und den Dienststellen der Bewegung, wobei besonders die SA unter Stabschef Röhm Strafverfahren gegen ihre Mitglieder durch ungesetzliche Eingriffe in die Rechtspflege verhinderte. Da es sich bei den Straftaten auch um Delikte aus eigennützigen und niederen Motiven handelte, empfanden selbst die nationalsozialistischen Landesjustizchefs diese Behinderung der Justiz als Untergrabung der Staatsautorität. Dabei wirkte sich auf die Justiz lähmend aus, daß Röhm ihr und den betroffenen SA-Einheiten gegenüber die Errichtung einer eigenen SA-Strafgerichtsbarkeit als beschlossene Sache hinstellte, bis zu deren Einführung alle Strafverfahren gegen seine Leute aufgeschoben werden sollten. Das Reichsjustizministerium, das die Errichtung einer SA-Sondergerichtsbarkeit zu verhindern trachtete, bestand jedoch gegenüber den Landesjustizchefs darauf, daß bis zur Klärung dieser Frage im Interesse der Staatsautorität und der Rechtssicherheit auch gegen SA- und SS-Angehörige Verfahren nach den geltenden Gesetzen durchzuführen seien. Da wegen Hitlers zögernder Haltung gegenüber der SA-Führung eine grundsätzliche Entscheidung in dieser Frage nicht zu erreichen war, konnten sich die Landesjustizchefs nur dadurch helfen, daß sie mit den regionalen SA-Stellen über jeden strittigen Fall „verhandelten“. Als Hans Frank in Bayern diese Praxis durch ein förmliches Verfahren regeln wollte, bei der der SA eine Art Mitwirkungsrecht an der Strafjustiz eingeräumt worden wäre, wurde er vom Reichsjustizministerium daran gehindert. Das Reichsjustizministerium, das die Gefahr erkannte, die eine Befreiung der SA-Armee von der Unterstellung unter die ordentliche Strafgerichtsbarkeit für die Rechtsordnung darstellte, wirkte seit Juli 1933 zusammen mit dem Reichsinnenministerium der Errichtung einer SA-Strafgerichtsbarkeit in geschickten Verhandlungen entgegen, bis das Problem mit der plötzlichen Beseitigung Röhms am 30.Juni 1934 aus der Welt geschafft war. Wenngleich letztlich Hitlers Haltung maßgebend war, darf die zähe Opposition des Reichsjustizministeriums in dieser Frage nicht als bedeutungslos angesehen werden. Die über $\mathbf{4 0 0 0}$ steckengebliebenen Strafverfahren gegen SA- und SS-Angehörige fanden nunmehr ihre Erledigung, wobei allerdings das anläßlich der Vereinigung der Ämter des Reichspräsidenten und des Reichskanzlers nach Hindenburgs Tod erlassene Straffreiheitsgesetz vom 7.August 1934 entlastend wirkte, das neben der Masse unpolitischer Straftaten auch „Übereifertaten“ für den Nationalsozialismus - jedoch keine Tötungsdelikte - berücksichtigte, soweit sie keine gemeine Gesinnung des Täters offenbarten.

Bei seiner Vereinigung mit dem preußischen Justizministerium im Oktober 1934 übernahm das Reichsjustizministerium die im Juli 1933 u.a. für die Behandlung der „strittigen“ Straffälle eingerichtete preußische Zentralstaatsanwaltschaft, die bis dahin gegen den Widerstand örtlicher Parteistellen einige aufsehenerregende Prozesse - u.a. gegen SS-Angehörige wegen Mißhandlungen im Lager Bredow bei Stettin - durchgesetzt hatte. Es zeigte sich allerdings, daß die Justiz nur dann durchgreifen konnte, wenn die Autorität der obersten politischen Führung - z. B. im Fall Bredow die Autorität Görings - hinter ihr stand. Das Reichsjustizministerium setzte 1934/35 die Zentralstaatsanwaltschaft vor allem bei der Verfolgung von Verbrechen in den frühen Konzentrationslagern ein, da sich Gürtner von der gerichtlichen Bestrafung eine mäBigende Wirkung auf die KZ-Bewacher erhoffte. Während die Zentralstaatsanwalt- 
schaft bei der Verfolgung einer Reihe von kleineren Fällen politischer Ausschreitungen erfolgreich war, konnte sie bei den KZ-Fällen nur ausnahmsweise Verurteilungen erzielen, da die Parteistellen eine Niederschlagung der Verfahren erreichten, für die Hitler als Staatsoberhaupt seit August 1934 ausschließlich zuständig war. In den wenigen dieser Fälle, in denen es zur Verurteilung kam, machte Hitler die gewünschte Wirkung zunichte, indem er den Tätern gegen den Willen des Reichsjustizministeriums nach kurzer Zeit die Verbüßung der Strafe erließ.

Als Ergebnis ist feststellbar, daß Reichsjustizminister Gürtner in der Phase der nationalsozialistischen "Revolution“ bereit war, Straftaten zugunsten der "nationalen“ Sache zu amnestieren, soweit sie nicht von niedriger Gesinnung zeugten und „nationale" Beweggründe nicht nur als Deckmantel benutzt wurden. Bei solchen Delikten und in den Fällen, die nach Abschluß der „Revolution“ das Rechtsbewußtsein und die Staatsautorität zu untergraben drohten, setzte Gürtner den Parteistellen Widerstand entgegen, der allerdings dort seine Grenzen fand, wo Hitler zugunsten seiner Anhänger entschied: hier wie bei anderen Gelegenheiten war Hitlers Weisung für den autoritär eingestellten Minister bindend, auch wenn sie seiner Überzeugung vom Recht widersprach. Die Justizbehörden waren grundsätzlich bestrebt, die Straftaten von Angehörigen der nationalsozialistischen Bewegung zu verfolgen, schon deswegen, weil die Bestimmungen der Strafprozeßordnung über den Verfolgungszwang fortgalten. Allerdings wurden die durch die Amnestiegesetze vorgesehenen Möglichkeiten zur Einstellung häufig vor allem dann wahrgenommen, wenn Strafverfahren wegen des Widerstandes der Parteiorganisationen nicht vorankamen. Sicher gab es Staatsanwälte, die auch in Fällen, die außerhalb der Fristen der Amnestiegesetze lagen, mit Einstellung des Verfahrens oder Vorschlägen zur Niederschlagung schnell bei der Hand waren, sei es, daß sie mit den Nationalsozialisten sympathisierten, sei es, daß sie sich lediglich Ärger mit den örtlichen Parteistellen ersparen wollten. Aber die zahlreichen Auseinandersetzungen und die Angriffe von seiten der Partei, denen Justizbeamte wegen ihrer Haltung in dieser Frage ausgesetzt waren, zeigen, daß sich die Justiz insgesamt in diesem Punkte nicht als willfähriges Werkzeug der nationalsozialistischen Bewegung erwies. Die Zentralstaatsanwaltschaft machte hiervon keine Ausnahme: bei ihr ist der Wille erkennbar, Rechtsbrüche auch höherer Parteifunktionäre zu verfolgen. Freilich hatte diese weisungsgebundene Behörde ebenso bei Niederschlagungen und Straferlassen mitzuwirken, wenn sie von der politischen Führung gefordert und von Hitler gegenüber dem Reichsjustizministerium angeordnet wurden.

Die Justiz sah sich aber nicht nur solchen ungesetzlichen Handlungen gegenüber, die individuelle Ausschreitungen von Anhängern der nationalsozialistischen Bewegung darstellten, sondern auch solchen, die von der politischen Führung angeordnet wurden und von deren strafrechtlicher Verfolgung die Justiz von vornherein ,ausgeschaltet" blieb. Dazu gehörten jene Tötungen ohne Gerichtsverfahren, die die SS und die Gestapo bei der „Röhm-Aktion“ vom 30.Juni 1934 zur angeblichen Niederschlagung eines unmittelbar bevorstehenden Putsches der SA-Führung durchführten. Als Rechtsgrundlage für die Nichtverfolgung dieser Taten durch die völlig überraschte Justiz konnten diesmal nicht Amnestie und Niederschlagung dienen, da sie das Eingeständnis der politischen Führung erfordert hätten, daß sie Verbrechen und Mord befohlen hatte. Gürtner, der in die Aktion nicht eingeweiht worden war und wie andere Reichsminister zunächst unter dem Eindruck stand, daß Hitler tatsächlich eine unmit- 
telbar drohende Gefahr für den Staat abgewendet habe - es handelte sich schließlich um die Beseitigung jener SA-Führerclique, die durch ihre selbstherrlichen Eingriffe in die Justiz die "revolutionären" Terrorakte ihrer Untergebenen deckte und bislang schon dadurch die Autorität des Staates untergraben hatte -, fand sich bereit, die von der Führung ergriffenen Maßnahmen durch ein Gesetz "als Staatsnotwehr rechtens“ zu erklären. Mit Hilfe dieses Gesetzes konnten die in einzelnen Tötungsfällen schon angelaufenen staatsanwaltschaftlichen Ermittlungsverfahren eingestellt werden; eine Einstellung ohne gesetzliche Grundlage - durch bloßen Befehl - hätte einer willkürlichen Praxis bei der Strafverfolgung für die Zukunft Tür und Tor geöffnet. Hier wird Gürtners öfter bekundetes Bestreben deutlich, ungesetzliche politische Vorgänge durch einmalige rechtliche Ausnahmeregelung aus der Welt $\mathrm{zu}$ schaffen, um das Recht - in diesem Falle den gesetzlichen Verfolgungzwang - grundsätzlich weiter aufrechtzuerhalten. Obwohl dieses Gesetz der Justiz die Möglichkeit bot, jene Morde zu verfolgen, die während der Aktion nicht zur „Niederwerfung des Putsches“, sondern von unteren Organen aus persönlichen Gründen verübt wurden und folglich durch Staatsnotstand nicht gedeckt waren, konnte Gürtner die gerichtliche Aburteilung solcher Morde bei Hitler nicht durchsetzen: wenngleich auch Hitler anerkannte, daß sie nicht unter das Gesetz fielen, erfüllte er Himmlers Wunsch und schlug diese Verfahren nieder. Gegen Gürtners Willen gewährte er auch den Verurteilten im Mordfall Kamphausen - im einzigen Prozeß, den Gürtner gegen Himmlers Widerstand durchsetzen konnte, um die Zuständigkeit und den unverminderten Anspruch der Justiz auf die Verfolgung krimineller Taten zu demonstrieren - durch Gnadenerweise bedingte Strafaussetzung.

Wie das Röhm-Unternehmen stellte auch der antijüdische Pogrom vom 9./10. November 1938 („Reichskristallnacht“) eine von der politischen Führung veranlaßte ungesetzliche Aktion dar. Außer der beabsichtigten Zerstörung jüdischer Synagogen und Geschäfte begingen Partei- und SA-Mitglieder Verbrechen aus eigennützigen Motiven und 91 Morde an Juden, teils in der Annahme, damit den unausgesprochenen Willen der Führung zu erfüllen, teils auf Befehl von Unterführern. Da die politische Führung die Bestrafung der von ihr bewirkten Handlungen vermieden wissen und nach außen hin die Behauptung einer nicht befohlenen, „spontanen“ Aktion der Bevölkerung aufrechterhalten wollte, forderte sie, daß die Staatsanwälte von der Untersuchung der Straftaten - die weitgehend im parteiinternen Milieu geführt werden mußte - ausgeschaltet blieben. Das Reichsjustizministerium wies daraufhin - im Gegensatz zur Röhm-Aktion diesmal ohne eine besondere gesetzliche Grundlage - die Staatsanwaltschaften an, die Brandstiftungen und Sachbeschädigungen an jüdischem Gut nicht zu verfolgen, bei den anderen Verbrechen aber die Ermittlungen der politischen Polizei zu überlassen und deren Vorlage abzuwarten. Nachdem jedoch die Parteigerichtsbarkeit der NSDAP auf Geheiß der politischen Führung an der Entscheidung der Staatspolizei über die Verfolgung der einzelnen „Übereifertat" durch die Justiz beteiligt und darüber hinaus mit der Beantragung einer eventuellen Niederschlagung bei Hitler beauftragt worden war, protestierte das Justizministerium vergebens gegen den Entzug der Entscheidung über diese Anträge. Das Oberste Parteigericht belegte die Ermordung von Juden nur mit geringen Disziplinarstrafen und erreichte bei Hitler die Niederschlagung, für die das Justizministerium nunmehr weisungsgemäß nur noch den angeforderten formalen Antrag vorzulegen hatte. Daß die Justiz meist nur Sitt- 
lichkeitsverbrechen an Juden, die den Tatbestand der „Rassenschande“ erfüllten, und Fälle größerer persönlicher Bereicherung aburteilen durfte, zeigt abermals deutlich, daß sie nur noch unter dem „Vorbehalt des Politischen“ arbeitete. Wenngleich sich Gürtner bei dieser „Sonderaktion“ der politischen Führung abermals mit einer Ausschaltung der Justiz abfand, weigerte er sich doch, das hier gehandhabte Verfahren für „normale" Zeiten zuzulassen und in den Reformentwurf einer neuen Strafprozeßordnung die Bestimmung aufzunehmen, daß Straftaten von Angehörigen der Bewegung „in Erfüllung von Parteiaufgaben“ nur mit der Zustimmung des Stellvertreters des Führers verfolgt werden sollten.

Von der im Herbst 1939 beginnenden Euthanasie - der geheimen „Vernichtung lebensunwerten Lebens" in den Heil- und Pflegeanstalten -, die gleichfalls eine von der politischen Führung angeordnete und gegen die Strafgesetze verstoßende Aktion darstellte, erfuhr das Reichsjustizministerium erst im Sommer 1940 durch Berichte seiner nachgeordneten Behörden und von kirchlicher Seite. Gürtner forderte, die von der „Kanzlei des Führers der NSDAP“ mit Hilfe von Tarnorganisationen durchgeführte Aktion einzustellen oder sie durch gesetzliche Garantien und geordnetes Verfahren nach Art der Erbgesundheitsgerichte zu regeln. Als er aber erfuhr, daß Hitler ein Gesetz aus politischen Gründen abgelehnt hatte, und Reichsleiter Bouhler ihm Ende August 1940 Hitlers Euthanasie-„Erlaß“ vom 1.September 1939 vorlegte, gab Gürtner seinen Widerspruch auf. Freisler wies diejenigen Generalstaatsanwälte, die eingegangene Strafanzeigen wegen Mordes in den Anstalten meldeten, zunächst einfach an, sie als Berichtssachen ans Ministerium zu leiten und weitere Verfügungen abzuwarten. Um die verantwortlichen Stellen von der Unmöglichkeit einer Durchführung der Aktion ohne gesetzliche Regelung zu überzeugen, führte Gürtner ihnen wiederholt die Schwierigkeiten und Störungen vor Augen, denen die von Amts wegen nicht informierten Gerichte und Staatsanwaltschaften gegenüberstanden, und wies auf die Beunruhigung hin, die die nicht geheim zu haltende Aktion unter der Bevölkerung auslöste. Erst nach Gürtners Tod setzte Staatssekretär Schlegelberger durch, daß die Oberlandesgerichtspräsidenten und Generalstaatsanwälte Ende April 1941 auf einer Tagung in Berlin vertraulich von der Aktion unterrichtet und die Staatsanwälte auf der „Rechtsgrundlage“ von Hitlers Erlaß angewiesen wurden, alle Anzeigen unbearbeitet dem Ministerium einzureichen, um die Strafverfolgung der von der politischen Führung beauftragten Ärzte und Pfleger zu verhindern. Dieser Zustand blieb bestehen, bis die Aktion der Massenvergasung wegen der wachsenden Unruhe in der Bevölkerung, der andauernden kirchlichen Proteste, der Behandlung in der ausländischen Presse und der Kritik in den eigenen Reihen über die Art ihrer Durchführung im Herbst 1941 eingestellt wurde.

Durch die Nichtverfolgung der von der Führung angeordneten ungesetzlichen Handlungen haben sich Gürtner und das Reichsjustizministerium an den begangenen Verbrechen mitschuldig gemacht. Ursache war, daß sie Hitlers uneingeschränkte „Führersouveränität“ anerkannten und sich deshalb auch seinem gegen die Strafgesetze verstoßenden und das Recht suspendierenden Willen beugten und ihn als rechtsverbindlich ansahen. Daß Hitler nichtstaatliche Organisationen und Organe - bei der Röhm-Aktion die SS, bei der „Reichskristallnacht“ die Partei und die SA, bei der Euthanasie eine Kanzlei der NSDAP - mit der Durchführung dieser Aktionen beauftragen konnte, die die Tätigkeit der Justiz als Teil des Staatsapparats ausschalteten, 
war Ausdruck der „Führersouveränität“, auf der das nationalsozialistische Herrschaftssystem nach seiner eigenen Verfassungstheorie beruhte: kraft geschichtlicher Sendung verkörperte der Führer "die politische Einheit und Ganzheit des Volkes“ und war oberster Träger der ungeteilten Macht. ${ }^{7}$ Als Reichskanzler und ab 1934 als Staatsoberhaupt war Hitler Inhaber der Staatsgewalt und Chef des Staatsapparates, der aber nur ein Träger hoheitlicher Gewalt war. Als Fübrer übte er die „Führergewalt“ über die nationalsozialistische Bewegung aus, die nach nationalsozialistischer Theorie nicht von der Staatsgewalt abgeleitet, sondern "originär" war. ${ }^{8}$ Die Bewegung baute durch die NSDAP mit deren Gliederungen und angeschlossenen Verbänden einen eigenen Apparat mit „hoheitlicher" Gewalt ${ }^{9}$ zur Durchsetzung des Führerwillens auf, dem Hitler zur Erfüllung bestimmter Aufgaben staatliche Funktionen übertragen konnte und der damit das bisherige Monopol des Staatsapparates auf legitime Gewaltanwendung brach. Während die staatlichen Behörden und Gerichte auf gesetzlich vorgeschriebener Grundlage, d.h. „normativ“ arbeiteten, brauchten sich die Organe der Bewegung, die Hitler zur Durchsetzung seines Willens einsetzte, keineswegs an das geltende Recht zu halten. Sie arbeiteten „außernormativ“. Ihr Instrument war nicht das Gesetz, sondern die „Maßnahme“; durch ihr Eingreifen suspendierten sie die Funktion der staatlichen Organe, die daher nur noch unter dem „Vorbehalt des Politischen“ wirkten. Die Erkenntnis, daß das nationalsozialistische Herrschaftssystem einen „Doppelstaat" - ein Ineinandergreifen von unter Vorbehalt arbeitendem „Normenstaat" und diesen bei Bedarf jederzeit suspendierendem „Maßnahmenstaat“ - darstellte ${ }^{10}$, ist für das Verständnis der Beziehungen der Justiz zu ihrem wichtigsten Kontrahenten, der SS und Polizei, wesentlich.

Die SS, der Hitler schon ab 1933 etwa bei der Bewachung der „regulären“ Konzentrationslager staatliche Funktionen übertragen hatte, entwickelte sich durch die Übernahme und Zentralisierung der politischen Polizeien der Länder, durch die Herauslösung der Polizei aus dem Ressort des Reichsinnenministeriums und ihre organisatorische Verschmelzung mit der SS unter dem „Reichsführer SS und Chef der deutschen Polizei“ Himmler sowie durch die Befreiung ihrer Tätigkeit von gesetzlichen Schranken zum mächtigsten Organ des Maßnahmenstaates. Gegen ihre schärfste Waffe, die polizeiliche Schutzhaft zur Festsetzung politischer Gegner ohne Bindung an die Bestimmungen der Strafprozeßordnung und ohne richterliche Entscheidung, die die Reichstagsbrandverordnung vom 28. Februar 1933 durch Begründung des zivilen Ausnahmezustandes rechtlich ermöglichte, hatten Gürtner und die führenden Beamten des Reichsjustizministeriums nichts einzuwenden, da sie als Anhänger eines autoritären Staates „liberalistische“ Rechtsanschauungen ablehnten und die Durchbrechung

7 Vgl. E. R. Huber, Verfassungsrecht des Großdeutschen Reiches, Hamburg 1939, S. 196.

${ }^{8}$ Vgl. a.a.O., S. 213 ff., 230 ff., und F. Neeße, Führergewalt. Die Entwicklung und Gestaltung der hoheitlichen Gewalt im Deutschen Reiche, Tübingen 1940, S. 45 ff.

9 Nachdem bereits vor der Übernahme der staatlichen Gewalt das „Hoheitszeichen“ und der Begriff des „Hoheitsträgers“ der Partei eingeführt worden waren, ist es in diesem Zusammenhang kennzeichnend, daß auch danach zwei Hoheitszeichen beibehalten wurden: der Hoheitsadler der Bewegung schaute vom Beschauer aus gesehen nach rechts, der Hoheitsadler des Staates in die entgegengesetzte Richtung, vgl. die von $\mathrm{He} ß$ und Frick unterzeichnete VO über die Gestaltung des Hoheitszeichens des Reichs v. 7.3.36 (RGBl. I, S. 145).

${ }^{10} \mathrm{Vgl}$. E. Fraenkel, The Dual State. A. Contribution to the Theory of Dictatorship, New York 1941; deutsch: Der Doppelstaat, Frankfurt a. M.-Köln 1974. 
rechtsstaatlicher Prinzipien für "nationale“ staatspolitische Ziele bejahten, zumal sie die Schutzhaft für eine vorübergehende Einrichtung hielten und von ihr zunächst vor allem die linke Opposition betroffen wurde. Nur sollten unsachgemäßer, willkürlicher Mißbrauch der Haft ausgeschlossen werden und die Schutzhäftlinge im Konzentrationslager insofern unter dem Recht stehen, als Mißhandlungen und Tötungen weiterhin als Straftaten geahndet wurden. Als das Reichsjustizministerium gewahr wurde, daß die Polizeihaft nicht nur zur präventiven Ausschaltung politischer Gegner, sondern als Dauereinrichtung zur „vorbeugenden Verbrechensbekämpfung“ gegen vorbestrafte unpolitische Kriminelle, auch gegen nicht straffällige Personen, die „die Allgemeinheit gefährdeten", wie Asoziale, Arbeitsscheue usw., vor allem aber als Strafe zur selbständigen Ahndung politischer wie unpolitischer Straftaten eingesetzt wurde, versuchte es gegen diese Ausweitung der Polizeihaft vorzugehen, konnte aber gegen den Machtfaktor SS nichts mehr ausrichten. Die auf Drängen der Justiz vom Reichsinnenministerium - das die Auswüchse der Schutzhaft gleichfalls einzuschränken suchte erlassenen, internen Schutzhaftbestimmungen vom April 1934, die die Verhängung von Schutzhaft für strafbare Handlungen als unzulässig erklärten, wurden von der Gestapo in diesem Punkt einfach ignoriert. Der Versuch Reichsinnenminister Fricks, der SS-Führung die Zuständigkeit für die politische Polizei im Verlauf der „Verreichlichung" wieder zu entziehen bzw. die Gestapo seinem Ministerium unterzuordnen, auch um ihre Tätigkeit gegenüber der Justiz abzugrenzen, mißlang. Im Gegenteil setzte Himmler gegen den Widerstand der beiden Reichsministerien im Gestapo-Gesetz vom Februar 1936 durch, daß die politische Polizei aus der inneren Verwaltung ausgegliedert blieb und statt des vom Reichsjustizministerium angestrebten Rechtsmittelzuges gegen Verfügungen der Gestapo deren Maßnahmen gesetzlich von der gerichtlichen Nachprüfung ausgenommen wurden. Gürtners Forderung, die Schutzhaft wenigstens dadurch zu „verrechtlichen“, daß Schutzhäftlinge gegenüber den Gestapobehörden durch Rechtsanwälte vertreten werden konnten, wurde von Himmler unter Berufung auf Hitler abgelehnt. Obwohl das Justizministerium auch in die neuen Schutzhaftvorschriften vom Januar 1938 die Aufnahme einer Bestimmung erreichte, daß Schutzhaft nicht zu Strafzwecken angeordnet werden dürfe, vermochte es nichts mehr daran zu ändern, daß die Polizeiführung die Schutzhaft immer dann zur „Korrektur" der Rechtspflege einsetzte, wenn sie der Ansicht war, daß die Justiz den Willen der politischen Führung nicht entschieden genug berücksichtigt hatte. Die Gestapo gab zudem häufig polizeilich ermittelte Strafsachen nicht an die Staatsanwaltschaft weiter, um Straftaten durch Schutzhaft selbst zu ahnden, aber auch um unliebsame Prozesse zu vermeiden und Täter der Bestrafung zu entziehen. Hinter dieser Praxis stand das Ziel der SS- und Polizeiführung, das sie allerdings erst nach Gürtners Amtszeit entschieden anstrebte: daß die Polizei nicht mehr als Hilfsorgan der Staatsanwaltschaft arbeiten, sondern im Gegenteil die Funktion der Staatsanwaltschaft einschließlich der Anklage übernehmen sollte. Die Gestapo verhaftete ferner gerichtlich Verurteilte, die ihrer Ansicht nach zu milde bestraft worden waren, nach der VerbüBung der Freiheitsstrafe und nahm Freigesprochene unmittelbar nach der Urteilsverkündung in Haft. Die wiederholten Vorstellungen des Reichsjustizministeriums, daß dadurch die Rechtssicherheit, das Ansehen der Justiz und die Autorität des Richterspruchs geschädigt würden, waren vergebens, weil die Gestapo ihre Zugriffe stets zu staatspolizeilichen Präventivmaßnahmen erklären konnte, über die ihr die Entschei- 
dung allein zustand. Das resignierende Justizministerium fand sich schließlich bereit, mit der Gestapo Vereinbarungen zu treffen, die ein lückenloses Ineinandergreifen von Untersuchungshaft und Schutzhaft sowie die rechtzeitige Mitteilung über die Entlassung von Hoch- und Landesverrätern, Bibelforschern und „Rasseschändern“ aus der Strafhaft sowie über Entlassungen aus der gerichtlichen Sicherungsverwahrung garantierten.

Die konkurrierende und korrigierende Tätigkeit der Polizei wirkte sich auf die Rechtsprechung aus: um sich von der politischen Führung kein „Versagen“ vorwerfen zu lassen und die Justiz nicht einer weiteren Ausschaltung zugunsten der Polizei auszusetzen, wirkte das Reichsjustizministerium in bestimmten Bereichen auf die Verhängung schärferer Strafen und in geeigneten Fällen auf die Anwendung gerichtlicher Sicherungsverwahrung hin. Der Richter befand sich damit in der Zwangslage, entweder entgegen seiner gewissenhaften Abwägung - wenn auch innerhalb des gesetzlichen Strafrahmens - auf eine schwerere Strafe zu erkennen, als sie dem Maß der Schuld entsprach, oder die Korrektur durch die Polizei herauszufordern, die die Autorität der Justiz untergrub und den Anspruch der Polizei auf erweiterte Funktion bei der Strafverfolgung rechtfertigte. Da die Überführung eines freigesprochenen Angeklagten oder ,gerecht" Verurteilten ins Konzentrationslager für den Betroffenen unter Umständen den Tod bedeuten konnte, mußte der Richter in solchen Fällen selbst Unrecht tun, wenn er ihn den Unrechtsmaßnahmen der SS und Polizei entziehen wollte. Das zeigt die Pervertierung, der die Strafjustiz im „Doppelstaat“ unterlag.

Daß die Drohung einer erweiterten „Polizeijustiz“ im Falle des „Versagens“ der Justiz kein leeres Schreckgespenst war, zeigte sich, als die Polizei mit Kriegsbeginn von Hitler durch geheime Weisungen die Befugnis zugestanden bekam, kriminelle Straftäter ohne Gerichtsverfahren zu exekutieren und die Vollstreckung öffentlich bekanntzugeben. Den Einwand des durch Pressemeldungen völlig überraschten Justizministers, daß im Heimatgebiet kein Staatsnotstand herrsche und das wirksame Verfahren der Sondergerichte zur Aufrechterhaltung der inneren Sicherheit vollauf genüge, tat Hitler mit der Behauptung ab, daß sich die Gerichte den Verhältnissen des Krieges nicht gewachsen zeigten. Das Reichsjustizministerium empfand es als einen besonderen Autoritätsverlust für die Justiz vor der Öffentlichkeit, daß Hitler die Polizeiexekution auch zur Korrektur rechtskräftiger Urteile einsetzte und - allein aufgrund ihm vorgelegter einseitiger Pressemeldungen - Verurteilte zu diesem Zweck der Polizei überstellen ließ. Daß die öffentliche Bekanntgabe in diesen Fällen grundsätzlich von Erschießungen „auf der Flucht“ oder „wegen tätlichen Widerstandes“ sprach, stellte für die Justiz keine Lösung des Problems dar, weil der Bevölkerung die Wahrheit nicht lange verborgen blieb. Da die Rechtssicherheit durch diese Exekutionen noch stärker erschüttert wurde als durch die Schutzhaft, versuchte das Reichsjustizministerium jeweils, Hitler von der Stichhaltigkeit des Urteils zu überzeugen oder ihn über Möglichkeiten zu informieren, durch die Anwendung der außerordentlichen Rechtsbehelfe die gesetzlich vorgesehene Höchststrafe oder gerichtliche Sicherungsverwahrung zu erwirken. Diese Versuche scheiterten fast regelmäßig, und gegenüber dem Führerbefehl stellte das Ministerium auch hier seine rechtlichen Bedenken widerspruchslos zurück.

Im Jahre 1940 wurde die „Polizeijustiz“ generell auf die Verfolgung von Straftaten „fremdvölkischer" - zunächst polnischer, später auch sowjetischer - Zivilarbeiter im 
Reich durch geheime Weisungen ausgedehnt, die u.a. ohne gesetzliche Grundlage die Todesstrafe für Geschlechtsverkehr mit Deutschen vorsahen. Da das nicht unterrichtete Reichsjustizministerium - es sollte sich die Geheimweisungen der SS- und Polizeiführung erst unter Reichsjustizminister Thierack beschaffen können - die von seinen nachgeordneten Behörden gemeldeten Vorgänge für eigenmächtige Eingriffe der Gestapo hielt und die gesetzliche Zuständigkeit weiterhin beanspruchte, kam es zu einer zweispurigen und unterschiedlichen Strafverfolgung, je nachdem, ob die Ermittlungsergebnisse bei der örtlichen Staatspolizeistelle oder - entgegen den Weisungen der SS- und Polizeiführung an die unteren Polizeidienststellen - bei der zuständigen Staatsanwaltschaft landeten. Diese Zweispurigkeit erzeugte Reibereien zwischen Justiz und Polizei, die nach Gürtners Tod auch durch eine Aussprache Staatssekretär Schlegelbergers mit Himmler im Juni 1941 nicht beseitigt werden konnten. Die „Polizeijustiz“" erwies sich aber auch hier als wirksames Druckmittel auf die Rechtsprechung, die ab 1941 von Polen an Deutschen begangene - oft geringfügige - Straftaten durch Anwendung der Volksschädlingsverordnung und der Ende 1941 erlassenen Polenstrafrechtspflegeverordnung mit dem Tode bestrafte.

Während das Reichsjustizministerium ab 1933 wesentliche Einbrüche der Polizei in den Zuständigkeitsbereich der Justiz hinnahm, verringerten sich seine Einwirkungsmöglichkeiten auf Himmlers Tätigkeitsgebiet ständig. Mißlang der Versuch, das Schutzhaftwesen durch die Einrichtung einer gerichtlichen Nachprüfung der Gestapomaßnahmen einzudämmen, so scheiterten auch die Bestrebungen, der ungesetzlichen Behandlung der Gefangenen in den Konzentrationslagern entgegenzuwirken. Die Ausübung ihrer gesetzlich fortbestehenden Zuständigkeit, Tötungen und Mißhandlungen durch SS-Bewacher in den Konzentrationslagern strafrechtlich zu verfolgen, wurde der Justiz durch die Sabotage der Ermittlungen und die Niederschlagung der Verfahren durch Hitler de facto unmöglich gemacht. Die Bemühungen Gürtners, die Disziplinar- und Wachvorschriften in diesen Lagern humaner zu gestalten und den Vollzugsbestimmungen in den Justizgefängnissen anzugleichen, um die mit den Strafgesetzen unvereinbaren grausamen Strafen und den rigorosen Gebrauch der Schußwaffe abzustellen, scheiterten am Kompetenzschwund des Reichsinnenministeriums und an der Ablehnung durch Himmler. Durch die Einrichtung der SS- und Polizeigerichtsbarkeit im Oktober 1939, die das Reichsjustizministerium - im Gegensatz zur Forderung der SA-Führung auf eine eigene SA-Strafgerichtsbarkeit 1933/34 - nicht abwenden konnte, wurde der ordentlichen Justiz die Zuständigkeit für die Verfolgung von Straftaten des KZ-Personals auch gesetzlich genommen. Da diese Gerichtsbarkeit im April 1940 auf die Gestapo- und Kriminalbeamten ausgedehnt wurde, hatte die Justiz ferner keine Handhabe mehr, gegen Polizeibeamte vorzugehen, die bei der Ermittlung von Straftaten Aussagen durch Mißhandlungen erzwungen hatten. Schon seit 1937 erkannte das Justizministerium die „verschärfte Vernehmung“ als „rechtmäßige“ Methode der Polizei an, wenn sie von der Gestapozentrale angeordnet und „vorschriftsmäßig “ durchgeführt worden war, obwohl die erpreßten Ergebnisse in der Hauptverhandlung oft nicht verwertet werden konnten. Die Entmachtung der Justiz zugunsten von SS und Polizei hatten Gürtner und die leitenden Beamten seines Ministeriums ungewollt gefördert, indem sie 1933 die Betrauung der Polizei mit gesetzlich nicht beschränkten Befugnissen zur Bekämpfung von Gegnern des „nationalen“ Staates in einer - wie sie annahmen - vorübergehenden Ausnahmesituation widerspruchs- 
los billigten. Als sie sich der Konsequenzen dieser aus politischen Motiven erfolgten Durchbrechung rechtsstaatlicher Prinzipien bewußt wurden, hatte sich die Machtstellung der SS- und Polizeiführung so gefestigt, daß sie die Entwicklung nicht mehr aufhalten konnten.

Auf dem Gebiet der Justizgesetzgebung, besonders der Neugestaltung des materiellen Strafrechts, hoffte das Reichsjustizministerium unter Hitlers Regierung, die aufgrund des Ermächtigungsgesetzes mit einer unbeschränkten Gesetzgebungsgewalt ausgestattet war, jene längst fälligen und durchaus nicht nur von radikalen Strafrechtlern geforderten Reformen durchführen zu können, die im parlamentarischen System der Weimarer Republik wegen der instabilen Mehrheitsverhältnisse im Reichstag und des Pluralismus widerstreitender Rechtsanschauungen nicht vorangekommen waren. Dabei stimmten die Vorstellungen Gürtners und der leitenden Justizministerialbeamten, die als Reaktion auf die „Erweichung“ der Verbrechensbekämpfung durch „unangebrachte" Milde und auf die Schwächung der Strafrechtspflege und Staatsautorität in der Weimarer Zeit ein antiliberales Strafrecht anstrebten, das ein schärferes Vorgehen gegen das Verbrechertum und einen starken strafrechtlichen Schutz des "nationalen“ Staates gewährleisten sollte, in weiten Teilen überein mit den Forderungen der politischen Führung nach strafrechtlicher Sicherung ihrer Herrschaft, die von ihr in anmaBender Weise mit dem deutschen Volk gleichgesetzt wurde. In der Phase 1933/34, in der durch die Einführung neuer Tatbestände und schwererer Strafen diese Sicherung betrieben, aber auch Teile der beabsichtigten Strafrechtsreform vorweggenommen und notwendige Einzelmaterien geregelt wurden, kam es zwischen dem Reichsjustizministerium und Hitler nur einmal zu einer ernsten Meinungsverschiedenheit, als dieser im März 1933 erstmals ein rückwirkendes Strafgesetz forderte, um den Reichstagsbrandstifter zum Tode verurteilen zu können. Das Ministerium erhob Einwände unter Hinweis auf den Grundsatz nulla poena sine lege, der in der gesamten Kulturwelt mit Ausnahme der Sowjetunion und einiger asiatischer Staaten gelte. Da auch Reichspräsident Hindenburg zögerte, an einer entsprechenden Präsidialverordnung mitzuwirken, wartete Hitler bis nach Inkrafttreten des Ermächtigungsgesetzes, das ihm ermöglichte, das „Gesetz über Verhängung und Vollzug der Todesstrafe“ (Lex Lubbe) vom 29. März 1933 zu erlassen und sich so über die - nun nicht mehr wiederholten - Bedenken des Justizministeriums hinwegzusetzen. Nachdem diese Schwelle überschritten war, stieß der Erlaß rückwirkender Gesetze in den folgenden Jahren zumindest dann auf keine Einwände des Ministeriums mehr, wenn die Forderung von Hitler kam: so wurden im Juni 1936 das Gesetz gegen erpresserischen Kindesraub und im Juni 1938 das Gesetz gegen Straßenraub mittels Autofallen mit rückwirkender Geltung jeweils nach der begangenen Tat erlassen, um die Täter auf Geheiß Hitlers zum Tode verurteilen zu können.

Schon im Jahre 1933 erfüllte das Reichsjustizministerium aber auch eine langjährige, bereits in den StGB-Entwürfen von 1925 und 1927 aufgestellte Reformforderung, indem es durch das Gewohnheitsverbrechergesetz vom 24. November die gerichtliche Sicherungsverwahrung einführte, die eine vorbeugende Verbrechensbekämpfung ermöglichte. Daß diese später auch ins StGB der Bundesrepublik übernommene Einrichtung ab 1938 ihrem Zweck entfremdet und durch ihre erweiterte Anwendung zur Eindämmung der konkurrierenden „Polizeijustiz“ benutzt werden sollte, war bei Erlaß des Gesetzes nicht vorauszusehen. 
Eine Enttäuschung erlitt das Ministerium bei der Verfolgung eines seiner wichtigsten gesetzgeberischen Ziele, der Kodifikation eines neuen StGB. Die Inkraftsetzung des nach anfänglichen Kompetenzkonflikten mit dem führenden Parteijuristen Hans Frank durch eine Strafrechtskommission unter Gürtners Vorsitz in dreijährigen Beratungen fertiggestellten und 1937 in mehreren Kabinettssitzungen mit Hitler fast zur Hälfte durchgesprochenen Entwurfs scheiterte am Widerstand der Parteiführung. Der Entwurf, der im nichtpolitischen Strafrecht teilweise seit der Jahrhundertwende erhobene Forderungen erfüllte, fortschrittliche Gedanken verwirklichte und insoweit nicht außerhalb der Tradition der deutschen Strafrechtsreform stand, entsprach andererseits den Forderungen der nationalsozialistischen Führung nach Sicherung ihrer Herrschaft und Unterstützung ihrer politischen und ideologischen Ziele: er schuf ein engmaschiges Netz von Straftatbeständen - das durch die Aufhebung des Analogieverbots noch „lückenloser“ gemacht wurde -, erfaßte durch die Strafbarkeit schon des Beginns einer Tat den verbrecherischen Willen und sah weitgespannte Strafrahmen mit erhöhten Strafen nebst Ausdehnung der Todesstrafe vor, die dem Ziel der Generalprävention dienen sollten. Dennoch brach Hitler die Beratung des Entwurfs im Kabinett ab und verweigerte seine Verabschiedung, da nach Meinung der Parteiführung auch dieses neue StGB der nationalsozialistischen Bewegung zu enge Fesseln angelegt hätte und die Partei bei der Erfüllung ihrer Aufgaben gegen seine Bestimmungen hätte verstoßen müssen. Hitler hielt es offensichtlich für zu früh, das sich dynamisch entwikkelnde Herrschaftssystem des Nationalsozialismus in dauerhafte rechtliche Formen zu gießen, und lehnte aus diesem Grunde auch die Proklamation einer neuen Verfassung ab, die er noch im Januar 1937 öffentlich angekündigt hatte. ${ }^{11}$ Nach Beginn des Krieges neigte die politische Führung noch weniger dazu, sich durch erschöpfende Kodifikationen selbst zu binden. Unter diesen Umständen war auch Gürtners nochmaliger Versuch zum Scheitern verurteilt, den StGB-Entwurf nach Kriegsausbruch in Kraft setzen zu lassen, weil die Kriegsverhältnisse den Erlaß einer Anzahl in ihm enthaltener Bestimmungen notwendig machten. Damit hatte sich die Erwartung der leitenden Beamten des Reichsjustizministeriums, in Hitlers Staat eine umfassende und in sich geschlossene Strafrechtsreform verwirklichen zu können, endgültig zerschlagen. Sie mußten die Erfahrung machen, daß das im Grunde normenfeindliche Regime auf dem Gesetzgebungsgebiet nur dann schnell und effektiv handelte, wenn es im augenblicklichen Interesse der politischen Führung lag.

Das Strafrecht wurde unter Verwendung von Teilen des Reformentwurfs so weit novelliert, wie es die Bedürfnisse erforderten. Im Jahre 1935 wurde die Wahlfeststellung zugelassen und das Analogieverbot aufgehoben, um auch eine Tat bestrafen zu können, die zwar gegen kein bestimmtes Strafgesetz verstieß, aber „nach dem Grundgedanken eines Strafgesetzes und nach gesundem Volksempfinden Bestrafung" verdiente. Damit wurde der fundamentale Grundsatz des Rechtsstaates nullum crimen, nulla poena sine lege in sein Gegenteil nullum crimen sine poena verkehrt. Während Gürtner darin ein in Ausnahmefällen anzuwendendes Mittel sah, um einen Täter nicht straflos durch eine Gesetzeslücke schlüpfen zu lassen - wie es das Reichsgericht im

1 Vgl. Hitlers Reichstagsrede v. 30.1.37 (VB, Sonderausgabe der Süddeutschen und Münchener Ausg. v. 31.1.37, S.6). 
Kritik erregenden Urteil zum Mißbrauch von Münzfernsprechern vom Dezember 1933 hatte tun müssen -, nur weil der Gesetzgeber eine technische oder gesellschaftliche Entwicklung nicht vorausgesehen hatte, ging Freisler weiter: Nach seiner Auffassung von der Analogie als eigener „Rechtsquelle“ sollte dem Richter die Möglichkeit gegeben werden, jede Handlung zu bestrafen, die die politische Führung - die allein das "gesunde Volksempfinden“ authentisch interpretierte - bestraft sehen wollte. Mit der von Freisler angestrebten „Rechtsschöpfung aus dem gesunden Volksempfinden“ war die Rechtssicherheit ernsthaft gefährdet, da die Strafbarkeit einer Tat für den einzelnen nicht mehr sicher vorhersehbar war. Die konservativen Vertreter eines antiliberalen Strafrechts, die dem Staat durch die Zulassung der Analogie eine lückenlose Verfolgung des Rechtsbrechers ermöglichen wollten, förderten auch hier ungewollt eine Entwicklung, die sie nicht beabsichtigt hatten. Dank der einschränkenden Rechtsprechung des Reichsgerichts und der traditionellen, am Gesetz orientierten Ausbildung des deutschen Richters wurde von der Analogie allerdings nur vorsichtig Gebrauch gemacht. $\mathrm{Zu}$ ihrer Anwendung im politischen Strafrecht bestand auch kein Anlaß, da gerade hier die Tatbestände durch Novellen nahezu lückenlos bestimmt waren.

Mit dem im selben Jahr erlassenen Nürnberger „Blutschutzgesetz“ stellte die Gesetzgebung das Strafrecht in den Dienst der nationalsozialistischen Rassenideologie. Gürtner und die konservativen Mitglieder der Strafrechtskommission hatten 1934 die von Freisler vorgebrachte Forderung abgelehnt, die Eheschließung und den außerehelichen Geschlechtsverkehr zwischen Juden und „Ariern“ als Tatbestände in ein neues StGB aufzunehmen, da sie das Strafrecht für kein geeignetes Instrument hielten, um die von der politischen Führung angestrebte Unterbindung der „Rassenmischung“ zu verwirklichen. Auch in der Folgezeit griff das Reichsjustizministerium entsprechende Anregungen von Parteiseite unter Hinweis auf außenpolitische Bedenken nicht auf. Als Hitler während des Parteitages im September 1935 dem nach Nürnberg einberufenen Reichstag das "Gesetz zum Schutze des deutschen Blutes und der deutschen Ehre“ zur Annahme vorlegen ließ, das die herbeizitierten Referenten des Reichsinnenministeriums überstürzt hatten formulieren müssen, konnte Gürtner nur noch erreichen, daß der „rasseschänderische“ Geschlechtsverkehr statt ausschließlich mit Zuchthaus auch mit Gefängnis bestraft werden konnte. Von grundsätzlichen Einwendungen des Reichsjustizministers war bei Hitlers Entscheidung keine Rede mehr, obwohl das diskriminierende Gesetz gegen das Prinzip der Rechtsgleichheit der Staatsbürger vor dem Gesetz verstieß. Die vom Justizministerium Anfang 1940 durchgesetzte Ergänzungsverordnung, daß eine Frau bei „Rassenschande“ auch nicht wegen Begünstigung oder Teilnahme bestraft werden durfte, war angesichts der Schutzhaftpraxis der Gestapo ein fragwürdiger Erfolg.

Die Zahl der gesetzlichen Tatbestände, bei denen die Todesstrafe zwingend vorgeschrieben war oder ermöglicht wurde, stieg von 1933 bis zum Kriegsausbruch von 3 auf ca. 25 an und wuchs danach weiter. Daß die Rechtsprechung im Kriege ausuferte, war keine Folge der Freigabe der Analogie, sondern der nach Kriegsbeginn erlassenen Strafgesetze mit schwersten Strafandrohungen und weitgefaßten, auslegungsfähigen Tatbeständen nebst Einführung von „Tätertypen“, die den Richter gleichfalls von der strengen Bindung an den Buchstaben des Gesetzes lösen sollten. So sah die Verordnung gegen „Volksschädlinge“ vom September 1939 gegen den „Plünderer“, der auf 
einem kriegsbedingt verlassenen Grundstück fremdes Eigentum an sich nahm, sowie gegen den „Saboteur“, der durch Brandstiftung, Transportgefährdung usw. „die Widerstandskraft des deutschen Volkes" schädigte, ausschließlich die Todesstrafe vor. Der Rechtsbrecher, der den Fliegeralarm oder die Verdunkelung ausnützte, sowie grundsätzlich jeder, der eine Straftat unter Ausnutzung der besonderen Kriegsverhältnisse beging, sollte als „Volksschädling“ mit dem Tode oder mit Zuchthaus bestraft werden. Im Oktober 1939 erklärte die Verordnung gegen ,jugendliche Schwerverbrecher" generell alle Strafen auf Jugendliche über 16 Jahre für anwendbar, wenn der Täter die Reife eines über 18jährigen besaß und „der Schutz des Volkes“ es erforderte. Die Verordnung gegen "Gewaltverbrecher“ vom Dezember 1939 bestrafte denjenigen mit dem Tode, der bei einer Straftat eine Waffe „oder andere gleich gefährliche Mittel“ anwendete oder mit ihnen drohte, oder einen Verfolger mit Waffengewalt abwehrte. Sie eröffnete darüber hinaus die Möglichkeit, bei allen Delikten Versuch und Beihilfe wie die vollendete Tat zu bestrafen. Im Mai 1940 wurde die Geltung des deutschen Rechts rückwirkend auf Straftaten von Ausländern ausgedehnt, die sie im Ausland gegen deutsche Amtsträger und Soldaten begingen. Zu diesen Strafnormen der Justiz kamen weitere Verordnungen, die in der Zuständigkeit anderer Ressorts ausgearbeitet wurden und gleichfalls hohe Strafen für politische Tatbestände wie „Wehrkraftzersetzung", Abhören von Auslandssendern, Wirtschaftssabotage usw. vorsahen. Diese gesetzlichen Handhaben sollten dem Richter eine von der politischen Führung geforderte, den Kriegsverhältnissen angepaßte harte Rechtsprechung ermöglichen, um den als „Volksfeind“ angesehenen Straftäter, der „der kämpfenden Front in den Rücken fiel“, lückenlos zu erfassen und „auszumerzen“ sowie jeden Ansatz einer politischen Opposition im Innern von vornherein zu ersticken. Die rigorose Anwendung dieser Gesetze und die exzessive Auslegung ihrer generalklauselartig umschriebenen Tatbestände führten zumal in der zweiten Kriegshälfte zu Urteilen von unmenschlicher Härte, die in keinem Verhältnis zur Schuld standen und durch die sich die Justiz u.a. in den Dienst der nationalsozialistischen Ausrottungspolitik gegen Juden und „Fremdvölkische“ stellte. Die Grundlage für diese Rechtsprechung hatten Gürtner und die national-konservativen Ministerialbeamten des Justizministeriums mit den erwähnten Kriegsgesetzen von 1939 gelegt, da sie vom „Trauma von 1918“ und der Idee beherrscht waren, daß ein Zusammenbruch der Heimatfront diesmal unbedingt verhindert werden müsse und keinesfalls durch die Unzulänglichkeit der Justiz verschuldet werden dürfe. Das Streben nach einem antiliberalen Strafrecht, das nicht dem Gedanken der spezialpräventiven Resozialisierung, sondern überwiegend der Autoritätswahrung und der Abschreckung diente, mündete nach Kriegsbeginn in die Vorstellung von der notwendigen physischen Unschädlichmachung und „Ausscheidung“ des Rechtsbrechers aus der „Volksgemeinschaft“. Die Gesetzgebung des Reichsjustizministeriums von 1933 bis 1940 schuf somit ein materielles Strafrecht, das durch den Abbau rechtsstaatlicher Garantien neben einer verschärtten Bekämpfung der Kriminalität darauf zugeschnitten war, die nationalsozialistische Herrschaft zu sichern und ihre Ziele zu unterstützen.

Anders als beim materiellen Strafrecht beabsichtigte das Reichsjustizministerium bei den Gesetzgebungsarbeiten zum Bürgerlichen Recht - die im Rahmen dieser Arbeit unberücksichtigt bleiben sollen - keine Neugestaltung durch ein geschlossenes Gesetzgebungswerk in der Form eines neuen BGB. Die Anpassung an nationalsoziali- 
stische Rechtsvorstellungen erfolgte hier einmal mit Hilfe einer veränderten Auslegung der Generalklauseln durch die Rechtsprechung, die dabei von der Rechtswissenschaft durch die Entwicklung allgemeiner Grundsätze unterstützt wurde. Zum anderen wurden Teilbereiche des BGB neu geregelt, vor allem aber die übrigen Gebiete des materiellen Privatrechts, auf die sich die Zielsetzung der politischen Führung vordringlich richtete - das Arbeitsrecht, das Bauernrecht, das Urheber- und Patentrecht, das Wirtschafts- und das Handelsrecht -, durch zahlreiche Sondergesetze umgestaltet.

Auch auf dem Gebiet der Gerichtsverfassung kam trotz Vorarbeiten des Reichsjustizministeriums für ein neues Gerichtsverfassungsgesetz keine Gesamtreform zustande; auch hier wurden nur jene gesetzgeberischen Maßnahmen ergriffen, die den Bedürfnissen der politischen Führung entsprachen. $\mathrm{Zu}$ diesen Maßnahmen gehörten die Errichtung der Sondergerichte und des Volksgerichtshofs, denen der Gedanke zugrunde lag, für die Aburteilung politischer Strafsachen im Sinne des Regimes „zuverlässige“ Gerichte zu schaffen und sie mit einem wirksamen Verfahren auszustatten. Die im März 1933 gebildeten Sondergerichte sollten durch den Wegfall der gerichtlichen Voruntersuchung und des Eröffnungsbeschlusses, einer auf 24 Stunden verkürzbaren Ladungsfrist und sofortiger Rechtskraft des Urteils eine schnelle Bestrafung des Täters und die unmittelbare Vollstreckung des Spruches ermöglichen. Waren diese Gerichte anfänglich als vorübergehende Instrumente zur Bekämpfung der im Frühjahr 1933 aufgetretenen bzw. erwarteten oppositionellen Handlungen gedacht und ihre Zuständigkeit daher zunächst auf bestimmte politische Straftaten beschränkt, so wurden sie bald auch zur Ahndung schwerer Fälle unpolitischer Kriminalität eingesetzt und ihre Zuständigkeit im Kriege - teilweise als Reaktion auf die konkurrierende „Polizeijustiz“ - ständig erweitert, so daß sich der Schwerpunkt der Strafjustiz von den ordentlichen Gerichten auf die Sondergerichte verlagerte. Damit nahm die Sondergerichtsbarkeit eine Entwicklung, die bei ihrer Einrichtung keineswegs beabsichtigt gewesen war. Die notwendige Vermehrung dieser Gerichte bzw. ihrer Kammern bewirkte aber auch, daß sie mit weniger „zuverlässigen“ Richtern besetzt werden mußten, ihre Rechtsprechung uneinheitlicher wurde und sie den von der Führung gewünschten Charakter von "Standgerichten der inneren Front" weitgehend verloren. $\mathrm{Da}$ es sich bei den Sondergerichten um eine Art „Spezialstrafkammern“ innerhalb der Landgerichte handelte, konnte die sonst bei Ernennungen und Beförderungen beteiligte Partei auf ihre Besetzung keinen unmittelbaren Einfluß nehmen.

Die Errichtung des Volksgerichtshofs, der anstelle des Reichsgerichts die Aburteilung der Hoch- und Landesverratssachen übernahm, erfolgte durch Gesetz vom April 1934 auf Forderung Hitlers und der politischen Führung, auch als Reaktion auf die monatelange Dauer, die „umständliche“ Verhandlungsführung und das „magere“ Ergebnis des Reichstagsbrandprozesses vor dem Reichsgericht. Der Gerichtshof, dessen Mitglieder von Hitler auf Vorschlag des Reichsjustizministeriums ernannt wurden - die ehrenamtlichen Mitglieder wurden dem Ministerium wiederum von anderen Staats- und Parteistellen namhaft gemacht -, war bei seiner Errichtung noch keineswegs jenes „Blutgericht“, zu dem es sich im Kriege entwickelte: nicht umsonst hatte das Reichsjustizministerium bei der Besetzung im Juni/Juli 1934 einen mehrwöchigen Kampf um die von ihm vorgeschlagenen Berufsrichter führen müssen, die entweder keine Parteigenossen oder nur „Märzgefallene“ waren. Während das Gericht 1934/35 noch eine gemäßigte Rechtsprechung aufwies, trat auch hier eine bei seiner Gründung 
nicht beabsichtigte Entwicklung ein. Unter Thierack, der 1936 - als der Volksgerichtshof zum ordentlichen Gericht im Sinne des GVG erhoben und mit eigenen Planstellen für die Volksgerichtsräte versehen wurde - zum Präsidenten ernannt wurde, verschärfte sich die Rechtsprechung und erreichte in dieser Hinsicht ab 1942 unter Freisler einen Höhepunkt, der das Gericht zu einem Instrument politischer Zweckmäßigkeit werden ließ.

Weitere Schritte auf dem Gebiet des Gerichtsverfassungsrechts, die der „geeigneten" Zusammensetzung der Gerichte dienten, unternahm das Reichsjustizministerium mit zwei Gesetzen vom April 1933 und Dezember 1934, die die noch in der Weimarer Zeit gewählten Schöffen und Geschworenen durch neue ersetzten und das Verfahren bei der Bestellung von Laienbeisitzern unter Ausschluß von Juden und „Volksfeinden" von diesem Amt änderten. Eine entscheidende Maßnahme in diese Richtung war die Beseitigung der Präsidialverfassung und der Selbstverwaltung der Gerichte, die im März 1935 zunächst bei den Amtsgerichten und im November 1937 bei sämtlichen Gerichten erfolgte. Sie entzog die Geschäftsverteilung, die zu Beginn eines jeden Jahres im voraus vorgenommen wurde, der Kollegialentscheidung unabhängiger Richter, machte sie zu einer Angelegenheit der Justizverwaltung und übertrug sie dem Gerichtspräsidenten, der die Geschäftsverteilung „im Interesse der Rechtspflege“ nunmehr auch während des laufenden Geschäftsjahres ändern konnte. Da diese Ermächtigung eine Gefährdung der Unabhängigkeit der Rechtsprechung bedeutete, ordnete Gürtner an, daß für diese Änderung die Weisung des Ministeriums einzuholen war, um ihren zurückhaltenden Gebrauch zu erreichen. Immerhin hatte sich das Reichsjustizministerium damit die gesetzliche Möglichkeit geschaffen, über den in Verwaltungssachen weisungsgebundenen Gerichtspräsidenten auf die Zusammensetzung der Spruchkörper Einfluß zu nehmen und z. B. einen "scharfen“ Richter ins Strafgericht oder einen unliebsamen Richter ins Grundbuchamt versetzen zu lassen. Mit dieser Ermöglichung einer Versetzung innerbalb eines Gerichts gelang es Gürtner, Hitlers weitergehende Forderung auf gesetzliche Einführung einer Zwangsversetzung des Richters an ein anderes Gericht wegen eines von ihm gefällten Urteils aufzufangen, die die persönliche Unabhängigkeit des Richters in weit stärkerem Maße beeinträchtigt hätte.

Mit den ersten nach Kriegsausbruch auf dem Gebiet der Gerichtsverfassung erlassenen Gesetzen beabsichtigte das Reichsjustizministerium, teils dem durch Einberufungen verursachten Personalmangel zu begegnen, teils Reformpläne zu verwirklichen. Die 1. Vereinfachungsverordnung vom 1. September 1939 ermächtigte das Ministerium, jeden Richter auch zu staatsanwaltschaftlichen oder Verwaltungsaufgaben an ein anderes Gericht abzuordnen. Da diese Abordnung ohne zeitliche Begrenzung einer unfreiwilligen Versetzung gleichkam, die bislang nur bei einer Änderung der Gerichtsorganisation erlaubt gewesen war, wurde im Zeichen des mobilen Kräfteeinsatzes im Kriege schließlich doch die Unversetzbarkeit des Richters und damit ein wesentliches Element seiner persönlichen Unabhängigkeit beseitigt. Indem Gerichtsassessoren und andere zum Richteramt befähigte Personen nicht nur bei den unteren Gerichten, sondern auch bei Oberlandesgerichten und beim Reichsgericht als nicht planmäßig angestellte Hilfsrichter verwendet wurden und sogar einer Kammer bzw. einem Senat vorsitzen durften, wurde jene Gruppe der Richterschaft vergrößert, die von vornherein keine persönliche Unabhängigkeit besaß. Die Verordnung schaffte ferner die Schöffen und Geschworenen ab und übertrug die Zuständigkeiten des Schöffengerichts auf den 
Amtsrichter als Einzelrichter sowie diejenigen des Schwurgerichts auf die nur noch mit 3 Berufsrichtern besetzte Strafkammer des Landgerichts, die zugleich erstinstanzliches Gericht und Berufungsgericht für die Urteile des Amtsrichters wurde. Während die Maßnahmen zur Mobilisierung und Einsparung von Kräften - auch die Strafsenate am Oberlandesgericht wurden von 5 auf 3 Berufsrichter verringert - kriegsbedingte Maßnahmen darstellten, entsprachen die Abschaffung der Schöffengerichte und der Schwurgerichte sowie die Beseitigung der Revision gegen die Urteile des Amtsrichters und gegen die Berufungsurteile der Strafkammer den langfristigen Reformabsichten des Reichsjustizministeriums. Gleichfalls nach den Reformplänen ordnete das Ministerium durch eine Verordnung vom Februar 1940 die Zuständigkeit zwischen dem Amtsrichter und der Strafkammer des Landgerichts auf neuartige Weise. Sie wurde nicht mehr durch die Art des Verbrechens und die gesetzlich angedrohte Strafhöhe bestimmt, sondern durch die Einführung der „Strafgewalt“ geregelt. Während die Strafgewalt der Strafkammer alle gesetzlichen Strafen und sichernden Maßregeln umfaßte, durfte der Amtsrichter keine Todesstrafe, keine Zuchthausstrafe über zwei Jahre, keine Gefängnisstrafe über fünf Jahre sowie keine Sicherungsverwahrung und keine Entmannung verhängen. Über die Zuständigkeit im Einzelfall entschied nunmehr der Staatsanwalt - der dazu eine Prognose über die zu erwartende Strafe anstellen mußte durch die Anklageerhebung vor dem entsprechenden Gericht, genauso wie er bis dahin schon über die Zuständigkeit zwischen Strafkammer und Sondergericht entscheiden konnte. Aber selbst wenn die Strafgewalt des Amtsrichters ausreichte, konnte er wichtige Sachen oder solche, für die ein Rechtszug zum Reichsgericht eröffnet werden sollte, vor der Strafkammer anklagen. Mit dieser Zuständigkeitsregelung konnte das Reichsjustizministerium über den weisungsgebundenen Staatsanwalt auf die Zuständigkeit der Gerichte Einfluß nehmen: der im Einzelfall zur Entscheidung berufene Richter und die gegen sein Urteil zur Verfügung stehenden Rechtsmittel waren im Augenblick der Tat nicht mehr gesetzlich festgelegt und im voraus bestimmbar. Dieser 1939/40 unter den Kriegsverhältnissen beginnende Abbau der gerichtsverfassungsrechtlichen Garantien für den Angeklagten sollte ab 1942 mit weiteren „Vereinfachungs"-Verordnungen seinen Fortgang nehmen und mit der Einrichtung von Standgerichten im Februar 1945 seinen Höhepunkt erreichen.

Die Hoffnung des Reichsjustizministeriums auf eine Gesamtreform des Strafpro$z e ß r e c h t s$, für die in mehrjährigen Kommissionsarbeiten der Entwurf einer neuen Strafverfahrensordnung fertiggestellt wurde, scheiterte aus denselben Gründen wie der Erlaß eines neuen StGB. Hans Frank und der NSRB lehnten den Entwurf des Justizministeriums von $1936 \mathrm{ab}$, da er den Gesichtspunkten der nationalsozialistischen Weltanschauung nicht entsprach und u. a. das Führerprinzip nicht konsequent durchführte. Die 1937 in einer Denkschrift des NSRB geforderte Aufnahme von Bestimmungen in die Strafprozeßordnung, daß Hitler als oberster Gerichtsherr dem Richter bei der Rechtsprechung Einzelweisungen erteilen dürfe, daß ferner die Rechtsmittel der Berufung und der Revision abgeschafft und richterliche Entscheidungen statt dessen durch justizfremde politische Stellen nachgeprüft und korrigiert werden sollten, waren für das Reichsjustizministerium unannehmbar. In seinem überarbeiteten Entwurf vom Mai 1939 suchte das Ministerium durch Kompromißlösungen die nationalsozialistischen Forderungen mit einem rechtlichen Verfahren in Einklang zu bringen. Das Führerprinzip wurde in die Rechtsprechung nur insoweit übernommen, als der 
Gerichtsvorsitzende in der Hauptverhandlung zwar Entscheidungen über Beweisanträge, Vereidigung, Ordnungsstrafen usw. allein treffen durfte, bei allen den Urteilsspruch betreffenden Entscheidungen aber weiterhin von der Mehrheit des Kollegialgerichts abhängig blieb. Berufung und Revision (in Form der aufgelockerten „Urteilsrüge") gegen Urteile wurden - unter Aufhebung des Verbots der reformatio in peius beibehalten. Der Forderung nach einer Möglichkeit, dem „gesunden Volksempfinden" nicht entsprechende Urteile auf Verlangen der politischen Führung zu korrigieren, wurde durch die Rechtsbehelfe des „außerordentlichen Einspruchs“ und der „Nichtigkeitsbeschwerde“ gegen rechtskräftige Urteile entsprochen. Da in beiden Fällen die Strafsache wiederum von einem Gericht neu entschieden wurde, war zumindest die Korrektur durch eine justizfremde Stelle vermieden. Die Stellung des Staatsanwalts im Verfahren wurde gestärkt. Da er selbst Haftbefehl erlassen und der Beschuldigte dagegen erst nach $z$ wei Wochen den Richter anrufen durfte, hätte sich die Justizverwaltung zugleich die Möglichkeit geschaffen, der konkurrierenden Polizeihaft zuvorzukommen, die häufig gerade mit der richterlichen Ablehnung der Untersuchungshaft begründet wurde. Zwar gelang es dem Reichsjustizministerium nicht, in ihrem Entwurf den Staatsanwalt auch gegenüber der Polizei zum „Herrn des Vorverfahrens" zu machen, doch konnte es die Forderungen der Polizeiführung abwehren, die Polizei von der gesetzlichen Verpflichtung einer rechtzeitigen Mitteilung der Straftat und Vorführung des Täters beim Staatsanwalt zwecks Entscheidung über den Haftbefehl zu entbinden und ihr nunmehr auch gesetzlich eine konkurrierende $\mathrm{Zu}$ ständigkeit für sichernde Maßregeln gegen Straftäter zuzuerkennen. Mit der Auflockerung der formstrengen Bestimmungen des Strafverfahrens zugunsten eines freieren Ermessens des Richters und des Staatsanwalts, der Beschleunigung des Prozesses und der verfahrensrechtlichen Ermöglichung einer besonderen Behandlung einzelner Fälle durch die erwähnten Rechtsbehelfe baute der Entwurf eine Reihe rechtsstaatlicher Garantien ab, die bisher zugunsten des Beschuldigten und seiner Verteidigung bestanden hatten. Obwohl der Entwurf somit ein geeignetes Instrument für die Rechtsanwendung im Sinne der politischen Führung darstellte und ohnehin eine Lockerung des Verfolgungszwanges auch bei der mittleren Kriminalität vorsah, scheiterte seine Inkraftsetzung durch Hitler an der Ablehnung der Parteiführung, da das Justizministerium die Einfügung einer Bestimmung verweigerte, daß auf Antrag des Stellvertreters des Führers die Verfolgung von Straftaten - ohne Beschränkung auf bestimmte Tatbestände oder einen beschränkten Personenkreis - im öffentlichen Interesse unterbleiben sollte. Angesichts dieser Unstimmigkeiten hielt Hitler wie beim materiellen Strafrecht auch eine grundsätzliche Neuregelung des Strafverfahrens für zu früh.

In den Jahren 1933/34 realisierte das Reichsjustizministerium einige seiner Reformpläne zum Strafverfahrensrecht durch Neuerungen, die noch Bestandteil der gegenwärtigen StPO sind, so der Nacheid und der Verzicht auf Vereidigung in bestimmten Fällen, das selbständige Sicherungsverfahren für die Unterbringung von Schuldunfähigen in einer Heil- und Pflegeanstalt - mit dem die Justiz die bisherige Alleinzuständigkeit der Polizei für die Unterbringung beseitigte - und die Aufhebung des Verbots der reformatio in peius für die Unterbringung bei Berufungs-, Revisions- und Wiederaufnahmeverfahren. Andere Änderungen im Strafverfahrensrecht beschnitten die Garantien des Beschuldigten, so die Ausdehnung des Schnellverfahrens vor dem Amtsrichter und dem Schöffengericht auf bestimmte politische Vergehen, die Beseiti- 
gung des Eröffnungsbeschlusses und der obligatorischen gerichtlichen Voruntersuchung in Hoch- und Landesverratssachen, die nunmehr in das Ermessen der Staatsanwaltschaft und des Gerichts gestellt wurde, sowie die Abschaffung des förmlichen Haftprüfungsverfahrens. In dieselbe Richtung wirkten die geschilderten besonderen Verfahrensvorschriften für die Sondergerichte sowie diejenigen für den Volksgerichtshof, denen auch Jugendliche unterworfen waren und die als eine Besonderheit die Genehmigung des gewählten Verteidigers durch den Gerichtsvorsitzenden vorsahen. Mit der Novelle vom Juni 1935 nahm das Reichsjustizministerium einen wichtigen Teil der beabsichtigten Strafverfahrensreform vorweg. Sie regelte die verfahrensmäßige Handhabung der gleichzeitig im materiellen Strafrecht zugelassenen Wahlfeststellung und der analogen Anwendung von Strafvorschriften und gewährte dabei dem Staatsanwalt in jedem Fall das Rechtsmittel der Revision - auf seinen Antrag hin sogar unmittelbar beim Reichsgericht -, um einer uneinheitlichen Rechtsprechung bei der Analogieanwendung vorzubeugen. Sie gab ferner dem Richter in Verfahren mit zwei Tatsacheninstanzen eine freiere Stellung bei der Beweiserhebung - der Amtsrichter, das Schöffengericht und das Landgericht als Berufungsinstanz durften einen Beweisantrag nach freiem Ermessen ablehnen - und hob damit das Verbot der vorweggenommenen Beweiswürdigung auf. Mit der generellen Beseitigung des Verbots der reformatio in peius beim Berufungs-, Revisions- und Wiederaufnahmeverfahren beabsichtigte das Ministerium, den „unnötigen“ Gebrauch dieser Rechtsmittel zum Zwecke der bloßen Verschleppung der Rechtskraft des Urteils zu verhindern. Die verfahrensmäßige Vereinfachung für das Reichsgericht, von einer vor dem Inkrafttreten der Novelle ergangenen Entscheidung über eine Rechtsfrage abzuweichen, sollte diesem Gericht die Anpassung an neue Rechtsanschauungen erleichtern. Mit dem Wegfall der gerichtlichen Voruntersuchung bei allen Gerichten, die nur noch auf Antrag des Staatsanwalts in Ausnahmefällen erfolgte, mit der Erweiterung der Gründe für die Untersuchungshaft und der Einführung der Hauptverhandlung gegen Flüchtige auch für schwere Straftaten zum Zwecke der Abschreckung wurde die Rechtsstellung des Beschuldigten weiter verschlechtert.

Da diese Novelle mit den als dringlich angesehenen Änderungen vom Reichsjustizministerium 1935 erlassen wurde, um die zu diesem Zeitpunkt noch in Aussicht genommene Gesamtreform der Strafverfahren in Ruhe vorbereiten zu können, wurden in den folgenden Jahren auf diesem Gebiet nur Einzelmaterien gesetzlich geregelt, so z. B. 1936 die Vernehmung von Angehörigen der NSDAP und ihrer Gliederungen, die bis dahin häufig Reibereien verursacht hatte. Als der Krieg Änderungen und Vereinfachungen im Strafverfahren erforderlich machte, verwandelte das Reichsjustizministerium Teile des von Hitler nicht in Kraft gesetzten Entwurfs einer neuen Strafverfahrensordnung in geltendes Recht, so u.a. die beiden außerordentlichen Rechtsbehelfe gegen rechtskräftig gewordene Urteile: Um die Forderung Hitlers erfüllen zu können, das auf Zuchthausstrafe lautende Urteil des Volksgerichtshofs gegen Ludwig Kompalla in ein Todesurteil umzuwandeln, strich das Reichsjustizministerium im September 1939 rückwirkend die mildernden Strafbestimmungen zum Landesverrat und führte gleichfalls rückwirkend den ,außerordentlichen Einspruch“ ein, auf dessen Einlegung durch den Oberreichsanwalt jedes Strafurteil aufgehoben und die Sache vor dem Besonderen Senat des Reichsgerichts oder - wenn es sich um ein Volksgerichtshofurteil handelte - des Volksgerichtshofs neu verhandelt wurde. Diesen Senaten sa- 
Ben jeweils die Präsidenten dieser Gerichte vor, um ein „zuverlässiges“ Urteil zu garantieren. Für Ausnahmefälle gedacht und in der Amtszeit Gürtners sparsam - beim Reichsgericht viermal - eingelegt, sollte der „außerordentliche Einspruch“ später als Instrument zur Verschärfung der Strafjustiz in zahllosen Fällen angewendet werden und damit das Schicksal anderer neugeschaffener Rechtseinrichtungen teilen, deren ausufernder Gebrauch das Recht zerstörte. Mit der im Februar 1940 eingeführten „Nichtigkeitsbeschwerde“ wollte das Reichsjustizministerium der bei Kriegsbeginn erfolgten drastischen Beschneidung der Rechtsmittel für besondere Fälle entgegenwirken sowie die Korrektur fehlerhafter Urteile und die Wahrung einer einheitlichen Rechtsprechung der Sondergerichte ermöglichen, auf die sich das Schwergewicht der Strafjustiz in zunehmendem Maße verlagerte. Die Nichtigkeitsbeschwerde konnte der Oberreichsanwalt wegen fehlerhafter Rechtsanwendung gegen Urteile des Amtsrichters, der Strafkammer und des Sondergerichts beim Reichsgericht einlegen, das im Falle einer Aufhebung des Urteils die Sache selbst entschied oder sie an das Erstgericht bzw. ein anderes Gericht zurückverwies. Während in Gürtners Amtszeit ca. 200 Nichtigkeitsbeschwerden eingelegt wurden - darunter von denjenigen, die Sondergerichtsurteile betrafen, die Hälfte zugunsten der Angeklagten -, vervielfältigte sich diese Zahl in den folgenden Jahren, vor allem nachdem ab August 1942 auch Tatsachenfeststellung und Strafzumessung mit der Nichtigkeitsbeschwerde angefochten und die Beschwerde auch durch die Generalstaatsanwälte bei den Oberlandesgerichten eingelegt werden durften. Da gleichzeitig die Beschwerden zugunsten des Angeklagten konstant abnahmen, wurde auch dieser Rechtsbehelf als Instrument zur rigorosen Verschärfung der Strafjustiz im Kriege angewendet. Mit derselben Verordnung vom Februar 1940 dehnte das Reichsjustizministerium das Schnellverfahren vor dem Amtsrichter auf Verbrechen aus und setzte es in der Folgezeit zur Ahndung von Arbeitsverweigerungen und Straftaten polnischer Zivilarbeiter im Reich ein, um mit der konkurrierenden Polizei auf diesem Gebiet Schritt halten zu können. Während diese Änderungen des Strafverfahrensrechts - zu denen die schon im September 1939 allen Gerichten gewährte Befugnis gehörte, Beweisanträge abzulehnen - mit den Reformabsichten des Reichsjustizministeriums im Einklang standen, waren die beiden Ermächtigungen, Entscheidungen über Anträge auf Wiederaufnahme des Verfahrens „bis auf weiteres" auszusetzen, und Freiheitsstrafen bis zu 6 Monaten auch im Strafbefehlsverfahren zu verhängen, reine Kriegsmaßnahmen.

Mit der Absicht, unter Auflockerung der formstrengen Regeln und der Erweiterung des richterlichen und staatsanwaltschaftlichen Ermessens ein Prozeßrecht zu schaffen, das eine straffe und schnelle, „autoritäre“ Strafjustiz ermöglichte, hatten Gürtner und die Vertreter eines antiliberalen Strafrechts im Reichsjustizministerium einen Weg beschritten, auf dem die schützenden rechtsstaatlichen Garantien abgebaut und die Rechtssicherheit und Verteidigungsmöglichkeit für den Beschuldigten eingeschränkt wurden - einen Weg, der durch weitere gesetzgeberische Maßnahmen ab 1942 bei einer Ordnung des Strafverfahrens endete, die zwar eine "nationalsozialistische“ Rechtsanwendung gewährleistete, aber in keiner Weise mehr Schutz gegen ungerechte Urteile bot.

Trotz der Einrichtung einer zentral geleiteten, straffen Reichsjustizverwaltung, der Neuregelung der Ausbildung und Auslese des Nachwuchses nach nationalsozialistischen Grundsätzen, des beamtenrechtlich ermöglichten Eingriffs in die persönliche 
Unabhängigkeit des Richters, der Einwirkung der Partei auf die Personalpolitik, trotz des Drucks, den die Polizei mit ihren Korrekturen auf die Tätigkeit der Justiz ausübte, und der Ausstattung der Justiz mit entsprechendem rechtstechnischem Rüstzeug auf den Gebieten des materiellen, des Gerichtsverfassungs- und Verfahrensrechts wurde der Justiz von der politischen Führung vorgehalten, daß sie ihre Aufgabe nur in ungenügender Weise erfülle und sich daher Korrekturen und dem Entzug von Zuständigkeiten unterwerfen müsse. Die Ursache dafür, daß Hitler - der an der Spitze seines Militär- und Polizeiapparates vorübergehend den europäischen Kontinent beherrschte die Justiz in seinem eigenen Lande trotz Gleichschaltungsmaßnahmen nur teilweise zu seinem Vollzugsorgan machen konnte, lag nicht zuletzt an der sachlichen Unabhängigkeit der Gerichte. Anders als bei der Exekutive, bei der die Ausführung des Willens der Führung durch eine geschlossene Befehlshierarchie bis zur untersten Ebene gesichert war, endete bei der Justiz der Befehlsweg vor dem weisungsfreien Richter; den Ausgang eines Prozesses hatte die politische Führung daher nie völlig in der Hand. Bildlich gesprochen: Während die auf den Gegner gerichtete Lanze der politischen Polizei gezielt ins Schwarze traf, hatte die Lanze der Justiz in der Institution der richterlichen Unabhängigkeit ein Gelenk, das unberechenbare Abweichungen verursachte. Dieses Problem durch eine kasuistische Gesetzgebung zu lösen, die möglichst jeden Tatbestand erfaßte und für ihn verbindliche Strafen vorschrieb - d.h. den an das Gesetz gebundenen Richter zu einem präzise funktionierenden Automaten machte, der den festgestellten Tatbestand lediglich unter eine der vielen Normen subsumierte -, war nicht möglich. Es hätte vorausgesetzt, alle Möglichkeiten der Entwicklung vorauszusehen und den Willen der Führung mit Hilfe der in dieser Hinsicht unvollkommenen menschlichen Sprache für alle Einzelfälle unmißverständlich niederzulegen. Wenn es die Umstände erforderten, daß sich dieser Wille im Einzelfall unvorhergesehen änderte, hätte sich überdies die Führung im Netzwerk der kasuistischen Gesetze selbst gefangen: die Entscheidung des Richters mußte in ihrem Sinne wiederum falsch ausfallen. Eine solche Gesetzgebung wurde daher von den führenden nationalsozialistischen Juristen abgelehnt. ${ }^{12}$ Die Gesetzgebung schlug vielmehr den entgegengesetzten Weg ein, in Vorsprüchen zu den Gesetzen Leitgedanken - Zielsetzungen - der Führung niederzulegen, die zur Auslegung der im Gesetz bewußt unbestimmt gehaltenen Tatbestände oder allgemein gehaltenen Wertmaßstäbe wie „gesundes Volksempfinden“, „Wohl des Reiches“, „völkische Belange“ usw. herangezogen werden sollten, um dem Richter ein elastisches Judizieren zu ermöglichen und das im Einzelfall von der Führung gewünschte Ergebnis zu erzielen. Da die Leitgedanken und Generalklauseln aber nur durch die politische Führung authentisch interpretiert wurden, bedurfte gerade diese Gesetzestechnik einer Lenkung der Rechtsprechung.

Die „volle Gleichheit der Grundeinstellung des Staatsführers und der einzelnen Richter", die als ideale Voraussetzung für die gewünschte Rechtsprechung angesehen wurde, war das Ziel der nationalsozialistischen Schulung und Erziehung der Juristen. ${ }^{13}$

12 Vgl. dazu u.a. R. Freisler, Richter und Gesetz, in: Die Verwaltungsakademie. Ein Handbuch für den Beamten im nationalsozialistischen Staat, hrsg. von $\mathrm{H}$. H. Lammers und H. Pfundtner, Berlin 1934 ff., Bd. I, Gruppe 2, Beitrag 17, S.2.

13 Vgl. a.a.O., S. 8 ff. Zum Problem der "richtigen“ Anwendung des positiven Rechts vgl. ders., Recht, Richter und Gesetz (DJ 1933, S.694 ff.), ferner u. a. C. Schmitt, Der Weg des deutschen Juristen (DJZ 1934, S. 691 ff.), und K. A. Eckhardt, Richteramt (DRWs 1936, S. 128 ff.). 
Dabei ging es laut Freisler nicht nur um eine verstandesmäßige Schulung, die den Richter befähigte, die Gesetze nach der nationalsozialistischen Weltanschauung, dem Parteiprogramm, programmatischen Kundgebungen Hitlers usw. ${ }^{14}$ auszulegen: auch dann hätte der Richter unter Berufung auf wirkliche oder vermeintliche „objektive“ weltanschauliche Forderungen mit seiner Entscheidung den Willen der Führung verfehlen können. Nach Freisler war nicht der nationalsozialistisch versierte Jurist das Ideal, sondern der „rechtskundige Nationalsozialist“"15, der das Recht „sicher erfühlte“ und ,instinktmäßig“ richtig anwendete, ein Richter, der jede andere Anschauung von Gerechtigkeit und Ordnung des menschlichen Zusammenlebens - religiöser, naturrechtlicher oder anderer Art - und jeden eigenständigen, objektiven Maßstab abgelegt, seine innere Unabhängigkeit gegenüber der nationalsozialistischen Führung aufgegeben hatte und sich ihr freiwillig und bedingungslos unterwarf. ${ }^{16}$ Trotz intensiver Versuche ideologischer Beeinflussung während der Ausbildung und in Schulungskursen des NSRB gelang es jedoch dem Regime bis zu seinem Ende nicht, das Erbe der traditionellen Juristenausbildung auszulöschen und beim Gros der Richter diese vielleicht stärkste Garantie für eine willfährige Rechtsprechung zu schaffen. Aber selbst eine weltanschaulich ausgerichtete Richterschaft hätte trotz guten Willens und aufrichtigen Bemühens das von der Führung Gewollte allein nicht immer treffen können. Denn die irrational konzipierte "nationalsozialistische Weltanschauung“ wurde unter der Dynamik des „ewigen Lebenskampfes“ ständig neu interpretiert und erhielt „überhaupt erst Realität und Bestimmtheit durch das Medium Hitler ${ }^{\text {“ }}{ }^{17}$ Daher konnte die Rechtsprechung nicht an ihr, sondern mußte am Zweckmäßigkeitsdenken der Führung orientiert sein: „richtig“" war eine Entscheidung nur dann, wenn sie in der konkreten Situation im Sinne der Führung zweckmäßig war. Der Richter durfte z. B. bei der nationalsozialistischen Auslegung des Gesetzes auch nicht zu weit vorprellen und damit an die Stelle des Gesetzgebers treten, da er nicht wissen konnte, aus welchen politisch-taktischen Gründen die Führung das Gesetz noch nicht geändert hatte und in welche Richtung sie das zu tun beabsichtigte. Aus diesen Gründen hätte auch ein ideologisch homogenes Richterkorps bei der Rechtsprechung der Lenkung bedurft, die allerdings dann leichter hätte bewerkstelligt werden können: das NS-Herrschaftssystem war mit der Institution des sachlich unabhängigen Richters schlechthin unvereinbar.

14 In den von Georg Dahm, Karl August Eckhardt, Reinhard Höhn, Paul Ritterbusch und Wolfgang Siebert gemeinsam formulierten und im Auftrag von Hans Frank am 14.1.36 auf der Tagung der Gesamtvertretung der deutschen Richter, Staatsanwälte und Rechtspfleger verkündeten „Leitsätzen über Stellung und Aufgaben des Richters“ heißt es u.a.: „Grundlage der Auslegung aller Rechtsquellen ist die nationalsozialistische Weltanschauung, wie sie insbesondere in dem Parteiprogramm und den Äußerungen unseres Führers ihren Ausdruck findet.“ DRWs 1936, S. 123; ferner R. Freisler, Nationalsozialistisches Recht und Rechtsdenken, Berlin 1938, S.67 f.

15 So Freisler auf der Bespr. Thieracks mit den Chefpräs. und GStAen im RJM am 29.9.42 (Akten des RJM, BA, Sign. R 22/4199).

16 „Sagt euch bei jeder Entscheidung, die ihr trefft: Wie würde der Führer an meiner Stelle entscheiden?", rief Hans Frank den Juristen in seiner Rede auf der Schlußkundgebung des Deutschen Juristentages 1936 zu (DR 1936, S. 213 ff.), S. 216.

17 Zum Verhältnis von Weltanschauung und charismatischem Führertum im NS vgl. M. Broszat, Der Staat Hitlers, München 1969, S. 49. 
Das radikalste Mittel, durch das die Rechtsprechung an den Willen der politischen Führung hätte gebunden werden können, wäre die formelle Aufhebung der Weisungsfreiheit des Richters gewesen - zumindest gegenüber Hitler als „Oberstem Richter“, wie sie in der erwähnten Denkschrift des NSRB von 1937 gefordert worden war. Da Hitler nach der nationalsozialistischen Staatsrechtstheorie die gesetzgebende, die vollziehende und die rechtsprechende Gewalt in seiner Hand vereinigte, hätte eine solche Weisung nicht als Eingriff der Exekutive, sondern als eine richterliche Handlung ausgelegt werden können. ${ }^{18}$ Bei der Weisung an den Richter, wie er bei der Feststellung des Sachverhalts die Zeugenaussagen würdigen, den Tatbestand rechtlich bewerten und welche Strafe er festsetzen, d.h. welches vorgeschriebene Urteil er verhängen sollte, hätte die Führung jedoch die Entscheidung jeweils ohne mündliche Verhandlung und Beweisaufnahme treffen müssen und den Richter damit seiner eigentlichen Funktion beraubt. In der Praxis hätte Hitler als „Oberster Richter“ aber nur einen Bruchteil der problematischen Fälle selbst entscheiden können und die Entscheidung - wenn sie keinem Gericht seines besonderen Vertrauens überlassen bleiben sollte - einer ihm zugeordneten Behörde, d.h. einem Organ der Exekutive delegieren müssen. Das Urteil des Richters wäre zur Verwaltungsmaßnahme, das Richteramt praktisch aufgehoben und der Richter zum Verwaltungsbeamten geworden, der bei einer Nichtbefolgung des Judikativbefehls die Konsequenzen zu tragen hatte. Sollte jedoch die Weisung geheim gegeben und die Fiktion eines richterlichen Verfahrens aufrechterhalten werden, konnte das Urteil nicht einmal offen mit der Entscheidung der Führung begründet werden, sondern mußte auf der Vortäuschung beruhen, der Richter habe aufgrund der Ergebnisse der Hauptverhandlung selbst entschieden. An dieser Verlogenheit mußte auf die Dauer aber der Charakter des Richters zerbrechen und die Gerichtsbarkeit zugrunde gehen. Wenngleich das Reichsjustizministerium in der Zeit nach Gürtner in Einzelfällen, bei denen Hitler interveniert hatte, Richtern die Erwartung Hitlers über das zu fällende Urteil mitteilte und damit de facto einer Weisung sehr nahe kam - unter Gürtner wurden diese Fälle durch die rückwirkende Einführung oder Verschärfung der Strafe für den betreffenden Tatbestand (erpresserischer Kindesraub 1936, Straßenraub mittels Autofallen 1938, Verrat von Staatsgeheimnissen ans Ausland 1939) gelöst, die eine Einwirkung auf den Richter erübrigte -, scheute es dennoch vor einer formellen Beseitigung des Instituts der richterlichen Weisungsfreiheit zurück, da sie auf die Öffentlichkeit im In- und Ausland eine äußerst ungünstige Wirkung hervorrufen und das Vertrauen des Volkes in die Rechtsprechung und die Rechtssicherheit erschüttert hätte.

Aus den gleichen Gründen wäre die Einführung einer allgemeinen Bestätigung der Urteile durch Hitler als "Oberstem Gerichtsherrn“ - analog der Militärjustiz im Kriege - problematisch gewesen. Denn Hitler hätte auch das Bestätigungsrecht nur in seltenen Fällen selbst ausüben können. Dieses Recht - und im Falle der Nichtbestätigung das Recht zur Abänderung des Urteils - hätte ebenfalls entweder auf Stellen der Verwaltung bzw. der Partei, wie es in der Denkschrift des NSRB von 1937 gefordert wurde, oder auf Organe der Justizverwaltung delegiert werden müssen. Den Gedanken einer Delegierung auf justizfremde Stellen lehnte das Reichsjustizministerium 1937 entschieden ab, da sie eine Entmündigung der Justiz und das Ende auch nur eines Mi-

${ }^{18} \mathrm{Zu}$ dieser Theorie von Hitler als „Oberstem Richter" vgl. S. $453 \mathrm{f}$. 
nimums an rechtsstaatlichem Verfahren bedeutet hätte. Als Schlegelberger nach Hitlers Kritik an der Justiz in der Reichstagsrede vom April 1942 vorschlug, das Justizministerium bzw. die Oberlandesgerichtspräsidenten zu ermächtigen, dem Strafausspruch eines rechtskräftigen Urteils die Bestätigung zu versagen, ihn ,im freien Verfahren“ abzuändern oder "die Sache zur anderweitigen Straffestsetzung an dasselbe oder an ein anderes Gericht" zu verweisen, lehnte die Parteiführung diesen Vorschlag ab, da sie sich von der Justizverwaltung kein energisches Eingreifen „in die - in altem Sinne aufgefaßte - Unabhängigkeit des Richters" versprach. Eine Einschaltung von Parteistellen in das vorgeschlagene Verfahren verwarf wiederum das Justizministerium, da die Bestätigungsentscheidung ausschließlich in seiner Verantwortung bleiben müsse. ${ }^{19}$

Das Reichsjustizministerium sah die einzig mögliche Lösung in einer „Steuerung“ oder „Lenkung“ der Rechtsprechung, die einerseits den Richter in die gewünschte Richtung beeinflussen, andererseits aber nicht unmittelbar in seine Entscheidung eingreifen und seine sachliche Unabhängigkeit nicht antasten sollte - ein Unterfangen, das der Quadratur des Kreises glich. Voraussetzung für die Lenkung war die seit 1933 ständig erweiterte Berichtspflicht der Staatsanwälte, die dem Ministerium eine Beobachtung der Vorgänge in den verschiedenen Bereichen der Strafrechtsprechung ermöglichte. Diese Informationspflicht betraf Hoch- und Landesverratssachen, Sondergerichtssachen, Verfahren von politischer Bedeutung, insbesondere gegen führende Persönlichkeiten, gegen katholische und evangelische Geistliche, gegen „Rasseschänder", wegen Abtreibung, ferner die Anwendung der Analogie, der Wahlfeststellung, der Volksschädlingsverordnung u.a. Die Maßnahmen, die das Reichsjustizministerium aufgrund der eingegangenen Berichte ergriff, waren von unterschiedlicher Intensität. $\mathrm{Zu}$ den allgemeinen Lenkungsmaßnahmen gehörten die kritische Besprechung von Entscheidungen im Amtsblatt des Ministeriums oder in juristischen Fachzeitschriften durch Referenten, ferner veröffentlichte Allgemeinverfügungen und unveröffentlichte Rundverfügungen, in denen den Staatsanwälten Richtlinien und Weisungen, den Richtern Empfehlungen und Hinweise für die Anwendung von Verfahrensvorschriften und Strafbestimmungen sowie für die Strafzumessung gegeben wurden. Diesen allgemeinen Maßnahmen sind auch die Tagungen und Besprechungen im Reichsjustizministerium zuzurechnen, auf denen den Chefpräsidenten und Generalstaatsanwälten, den Vorsitzenden der Hochverratssenate, der Sondergerichte und der für bestimmte Tatbestände zuständigen Strafkammern sowie den Oberstaatsanwälten mündliche Direktiven gegeben wurden, die sie an die Richter und Staatsanwälte weiterleiteten. Auf diesen Tagungen wurde besonders deutlich, daß die Lenkung häufig durch die Kritik der Polizeiführung und durch deren korrigierende Schutzhaftpraxis ausgelöst wurde und darauf abzielte, künftig das Mißfallen der politischen Führung an der Rechtsprechung zu vermeiden. Diese allgemeinen Lenkungsmaßnahmen - zu denen sich 1942 unter Thierack die bekannten „Richterbriefe“ gesellten - verletzten die

$19 \mathrm{Vgl}$. Schr. Schlegelbergers an Hitler v. 6.5.42 mit Erl.Entwurf und Schr. Bormanns an Lammers v. 10.6.42 (als Nürnbg. Dok. NG-102 abgedruckt in der Dokumentation von M. Broszat, Zur Perversion der Strafjustiz im Dritten Reich, VfZ 1958, S. 426 ff.), dazu Verm. Schlegelbergers für Lammers v. 9.5.42 über seine Bespr. mit Bormann (Akten der RK, BA, Sign. R 43 II/ $1560 \mathrm{~b})$ 
Weisungsfreiheit des Richters nicht, weil ihm die Beachtung der erhaltenen Hinweise im Einzelfall überlassen blieb: daß sie häufig wiederholt werden mußten, zeigt, daß sich die Richterschaft nicht sklavisch an sie gebunden fühlte.

Um den Ausgang eines laufenden Strafverfahrens zu beeinflussen, benutzte das Reichsjustizministerium in der Amtszeit Gürtners noch überwiegend die Weisungsgebundenheit des Staatsanwalts: gegen erstinstanzliche Urteile ließ es die Rechtsmittel der Strafprozeßordnung, gegen rechtskräftige Urteile die außerordentlichen Rechtsbehelfe einlegen. Zur individuellen Lenkung in wichtigen schwebenden Strafverfahren bediente sich das Ministerium noch nicht der später praktizierten direkten Einwirkung auf den Richter durch den Gerichtspräsidenten, der dem Richter in einer Besprechung des Falles vor der Hauptverhandlung - der sogenannten „Vorschau“ Empfehlungen gab, deren Nichtbeachtung in einer „Nachschau“ erörtert wurde. Der Richter selbst wurde unter Gürtner in Ausnahmefällen nur durch eine nachträgliche Urteilskritik angesprochen, die ihm in möglichst „kollegialer“ Form über seinen Dienstvorgesetzten vermittelt wurde. Die Einwirkung auf den Richter geschah vielmehr indirekt über den Staatsanwalt, der angewiesen wurde, einen bestimmten Strafantrag zu stellen und den Gerichtsvorsitzenden von der Weisung des Ministeriums vertraulich zu unterrichten. Zwar war der Richter, der das Urteil aufgrund der Ergebnisse der mündlichen Hauptverhandlung alleinverantwortlich zu fällen hatte, an den Antrag der Staatsanwaltschaft nicht gebunden. Dennoch geriet er durch diese Mitteilung unter erheblichen psychologischen Druck, vor allem dann, wenn er erkennen konnte, daß hinter der Weisung an den Staatsanwalt der Wille hoher politischer Stellen stand. Obwohl somit die allgemeinen und individuellen Lenkungsmaßnahmen des Reichsjustizministeriums unter Gürtner die Bestimmungen des Gerichtsverfassungsgesetzes und der Strafprozeßordnung über die Weisungsfreiheit des Richters nicht verletzten, beeinträchtigten sie seine sachliche Unabhängigkeit erheblich: erfüllte der Richter die Erwartungen des Ministeriums - vor allem in wiederholten Fällen - nicht, konnte er persönliche Nachteile wie Nichtbeförderung, herabwürdigende Versetzung, im Kriege Abordnung in ein Amt von geringerem Rang oder Aufhebung seiner Unabkömmlichkeitsstellung und Einberufung zur Wehrmacht, im extremen Fall sogar Verlust seines Amtes befürchten. Zusätzlich war der Richter häufig Einwirkungen justizfremder Stellen ausgesetzt: der drohenden Korrektur seines Urteils durch die Polizei mittels Schutzhaft und Konzentrationslager für den Angeklagten sowie Einschüchterungsversuchen der örtlichen Presseorgane und Dienststellen der Partei, die ihm wegen seiner Auffassung als Richter die Rolle des politischen Gegners zusprachen und darüber hinaus seine Personalangelegenheiten beeinflussen konnten. Mögen manche Befürchtungen vom Richter im Einzelfall auch nur subjektiv empfunden worden sein, so waren sie deshalb nicht minder wirksam. Diese kumulativ wirkenden Einflüsse erzeugten für den Richter eine Atmosphäre psychologischen Drucks, in der von einer sachlichen Unabhängigkeit nicht mehr gesprochen werden kann. Für diese Feststellung ist es unerheblich, daß zahlreiche Urteile ohne Beeinflussung ergingen und mancher Richter die Lenkung am eigenen Leibe nicht erfuhr. Denn die richterliche Unabhängigkeit ist unteilbar und entweder gegeben oder nicht. Bei der Konfrontation mit Lenkungsmaßnahmen und justizfremden Einwirkungen dürften jedenfalls nur starke Charaktere aus Gerechtigkeitsgefühl und innerer Überzeugung der Versuchung widerstanden haben, möglichen Unannehmlichkeiten aus dem Wege zu gehen und 
sich „anzupassen“. Neben den Fällen, in denen das Gesetz ausschließlich die Todesstrafe vorschrieb und der an das Gesetz gebundene Richter bei einwandfrei erfülltem Tatbestand und vorliegender Schuld nach seiner Überzeugung keine andere Wahl hatte, und neben dem Wirken fanatischer Richter, die als überzeugte Nationalsozialisten das Gesetz - sogar über den Wortlaut hinaus - zum Nachteil des Angeklagten auslegten und bis an die äußerste Grenze des vorgeschriebenen Strafmaßes gingen, sind zahlreiche ungerechte Urteile, insbesondere Todesurteile, auf diese Anpassung des gesinnungsmäßig nicht nationalsozialistischen Richters zurückzuführen ${ }^{20}$, der aus menschlicher Schwäche gegen sein Gewissen handelte oder es mit den "nationalen“ Erfordernissen des Krieges betäubte. Demgegenüber gab es aber auch Richter, die aus Gerechtigkeitsgefühl heraus in Gesetzesform gekleidetes Unrecht milderten, das Gesetz restriktiv auslegten und damit „unter dem Vorwand der Unabhängigkeit der Rechtspflege subversive Opposition gegen den einheitlichen Staats- und Führerwillen" trieben. ${ }^{21}$ So kommt es, daß nicht nur im Bagatellstrafrecht und in weiten Gebieten des bürgerlichen Rechts, sondern auch bei politisch gefärbten Strafsachen - selbst solchen, die von Sondergerichten verhandelt wurden - Urteile vorliegen, die vom rechtsstaatlichen Standpunkt nicht zu beanstanden sind, und die neben exzessiven Urteilen von barbarischer Härte stehen, die jeder Gerechtigkeit hohnsprechen. Aber die Feststellung, ob die damaligen Gerichte Instrumente des nationalsozialistischen Unrechtstaates waren, ist keine quantitative Frage: etwa in welchem Umfang die Gerichte mit ihren Urteilen ungerechten Forderungen der politischen Führung nachkamen oder in welchem Umfang sie mit ihren Entscheidungen eine rechtliche, auch gerechte, Ordnung aufrechterhielten - abgesehen davon, daß die jährlich gefällten ca. 300000 Strafurteile und ein Mehrfaches von Urteilen in Zivilsachen auf diesen Gesichtspunkt hin nicht nachgeprüft werden können. Entscheidend ist vielmehr, daß die politische Führung durch die geschilderten Mittel jederzeit auf die Rechtsprechung einwirken konnte, um das erwünschte Ergebnis zu erzielen, und die Rechtsprechungsorgane damit qualitativ Instrumente des Unrechtsstaates wurden, die dem einzelnen keinen rechtlichen Schutz mehr gewähren konnten.

Auch die Frage, ob die Justizverwaltung und an ihrer Spitze das Reichsjustizministerium bei der Verhinderung der nationalsozialistischen Diktatur und ihres Einbruchs in das Recht "versagt" haben, geht von falschen Voraussetzungen aus. Durch die Gesinnung ihrer führenden Beamten und die Entfernung der wenigen „Herzensrepublikaner" aus der Justizbeamtenschaft - von denen sich die meisten gegenüber den „Vernunftsrepublikanern“ im „Republikanischen Richterbund“ zusammengefunden hatten - war die Justiz 1933 kein Instrument, das sich für eine Verteidigung der freiheitlich-demokratischen Grundordnung von Weimar nebst deren politischen Prinzipien der Volkssouveränität, der Ablösbarkeit der Regierung und ihrer Verantwortlichkeit gegenüber der Volksvertretung, Bestand und Chancengleichheit politischer Parteien sowie Recht auf Bildung und Ausübung einer Opposition eingesetzt hätte. Aber auch die Beseitigung der rechtsstaatlichen Prinzipien dieser Grundordnung nahm die Justizverwaltung in der „Ausnahmesituation“ von 1933 zur Aufrichtung des von ihr

20 Zum Problem der Anpassung vgl. G. Gribbohm, Richter und Strafrechtspflege im Dritten Reich, in: Justiz im Dritten Reich, Sankelmark 1985, S. 33 ff.

21 So Hans Frank, a.a.O. (s. voranstehende Anm. 16). 
angestrebten autoritären Staates und in Verkennung der wahren, rechtszerstörerischen Absichten der Nationalsozialisten bereitwillig hin: Die beiden Prinzipien der Gesetzmäßigkeit der Verwaltung und der Achtung vor den persönlichen Grund- und Freiheitsrechten wurden durch die Reichstagsbrandverordnung zugunsten der politischen Polizei unter den „Vorbehalt des Politischen“ gestellt. Das Prinzip der Gewaltentrennung und das Prinzip der Verfassungsmäßigkeit der Gesetze - d.h. vor allem ihrer inhaltlichen Bindung an die in der Verfassung niedergelegten Rechtssätze wie Gleichheit des Bürgers, nulla poena sine lege usw. - wurden durch das Ermächtigungsgesetz aufgehoben. Mit der Lösung des Gesetzgebers von der Verfassung verzichtete die Justiz zugleich auf die richterliche Nachprüfung der Regierungsgesetze, da es über dem Willen der politischen Führung kein übergeordnetes Verfassungsgesetz mehr gab, an dem sie gemessen werden konnten; die Nachprüfung politischer Hoheitsakte der Führung auf ihre Gesetzmäßigkeit war mit der Auffassung vom autoritären „Führerstaat" ohnehin unvereinbar. Auf dem Gebiet der Justizgesetzgebung setzte sich das Reichsjustizministerium über die in der Verfassung verankerten Rechtssätze - teils auf Veranlassung der Führung (z. B. „Blutschutzgesetz"), teils von selbst (z. B. Einführung der Analogie) - ohne Hemmungen hinweg, nur beim Erlaß rückwirkender Gesetze äußerte es anfänglich Bedenken.

Mit der widerstandslosen Räumung dieser rechtsstaatlichen Positionen begab sich das Reichsjustizministerium aber zugleich der Möglichkeit, den eigenen Zuständigkeitsbereich der Justiz und das einzige rechtsstaatliche Prinzip, das es aus eigenem Antrieb zu bewahren suchte, wirksam zu verteidigen: die Unabhängigkeit der Gerichte. Es gelang dem Justizministerium nicht, den Eingriff in die persönliche Unabhängigkeit des Richters, der für die von der Führung geforderte Entfernung jüdischer und national „unzuverlässiger“ Justizbeamter unerläßlich war, 1933 auf einen einmaligen, kurzen „Säuberungsakt“ zu beschränken. Den mühsam errungenen Erfolg, diese persönliche Unabhängigkeit 1937 im Beamtengesetz wieder einigermaßen rechtlich abzusichern und diesen „Fortschritt“ in der Folge sogar gegenüber Hitler zu verteidigen, machte der Krieg mit seinen Ausnahmebedingungen wieder zunichte. Trotz gesetzlicher Aufrechterhaltung der richterlichen Weisungsfreiheit mußte das Reichsjustizministerium schließlich auch die sachliche Unabhängigkeit des Richters antasten, um den Forderungen der politischen Führung gerecht zu werden, und damit auch dieses rechtsstaatliche Prinzip aufgeben.

Bei den geschilderten Vorleistungen, die das Reichsjustizministerium aus „nationalen" Motiven schon 1933 erbracht hatte, waren in der Folgezeit seine Bemühungen, den Tätigkeitsbereich der Justiz gegen Eingriffe von außen abzuschirmen, ihre Ausschaltung bei der Verfolgung ungesetzlicher Handlungen sowie den endgültigen Entzug von Zuständigkeiten zu verhindern, wenig aussichtsreich. In diesen Bestrebungen darf seitens der Justiz - zumindest während der Amtszeit Gürtners - kein ausschließlich durch Ressortegoismus motivierter Kampf um Kompetenzen gesehen werden, wie er bei der formlosen Struktur des „Führerstaates“ $z$ wischen Institutionen und Organisationen von Staat und Partei an der Tagesordnung war. Bei den Auseinandersetzungen um die Eindämmung der „revolutionären“ Gewaltanwendung von Parteiorganen und die Beschränkung der außernormativen Tätigkeit der Polizei auf Vorbeugungsmaßnahmen ging es Gürtner darum, auch im „Führerstaat“ eine - autoritär geprägte - Rechtsordnung aufrechtzuerhalten bzw. wiederherzustellen, die dem einzel- 
nen Rechtssicherheit gewährte, und ein weiteres Abgleiten in die Willkür des Polizeistaates zu verhindern. Obwohl er dabei gelegentlich aus seinen ethischen und rechtlichen Beweggründen kein Hehl machte, mußte Gürtner den Machthabern gegenüber meist in ihrer Sprache sprechen und Argumente der Zweckmäßigkeit anführen, um sein Ziel zu verfolgen. Eine wesentliche Voraussetzung für eine erfolgreiche Verteidigung der Zuständigkeit gegen die konkurrierende Polizei - die der Justiz mit der Drohung weiteren Kompetenzentzuges im Nacken saß - war allerdings, daß sich die Justiz ihrerseits den Forderungen der politischen Führung anpaßte, was nicht ohne Preisgabe rechtlicher Prinzipien möglich war. Bei der Aufgabe, diese Forderungen in Formen zu bringen, die mit dem Rechtssystem im Einklang standen, gelang es der Autorität Gürtners, für die Justiz tragbare Kompromisse zu schließen, die die Aufrechterhaltung einer - wenngleich nicht unverbrüchlichen - Rechtsordnung gewährleisten konnten. Für manche Forderung fand er eine gemäßigte rechtliche Lösung, einige konnte er trotz des Wirkens Freislers im Ministerium abwenden, der als fanatischer Nationalsozialist die Justiz vorbehaltlos zu einem willfährigen Werkzeug der politischen Führung machen wollte. Auch Freisler wachte zwar gegenüber justizfremden Stellen eifersüchtig über die Kompetenzen der Justiz, stellte dabei aber den Ressortgedanken über den Rechtsgedanken. Um eine Aufgabe in der Zuständigkeit der Justiz zu halten bzw. zu übernehmen und dadurch ihre „Bewährung“ gegenüber der Führung zu demonstrieren, opferte er für deren Erfüllung bereitwillig herkömmliche Rechtsgrundsätze: hervorstechende Beispiele für die Zeit nach Gürtner sind die Strafrechtspflegeverordnung gegen Polen und Juden in den eingegliederten Ostgebieten, die ein materielles Sonderrecht schuf und dem Richter und Staatsanwalt das Abweichen vom Strafverfahrensrecht gestattete, und die Übernahme der „Nacht- und Nebel“-Fälle aus den besetzten westeuropäischen Ländern im Dezember 1941, die mit dem geltenden Prozeßrecht nicht zu erledigen waren und für die Freisler ein eigenes Verfahren ausarbeiten ließ, das die Prozesse zur reinen Farce machte. ${ }^{22}$ Die Abwicklung einer Sache im ,justizförmigen“ Verfahren beinhaltete nicht mehr ihre Behandlung nach den Maßstäben des Rechts. Aber auch schon unter Gürtner wurde das Reichsjustizministerium durch Anpassung auf den Weg des Unrechts gedrängt, denn sie bedeutete nicht nur passive Hinnahme der verbrecherischen, dem traditionellen Beamtenethos der Justiz widerstrebenden Praktiken des Regimes, sondern deren aktive rechtliche Abschirmung oder Normierung und damit Beteiligung am Unrecht. Jeder Kompromiß, mit dem das Ministerium Maßnahmen oder Forderungen der politischen Führung aufzufangen und mit dem Rechtssystem in Einklang zu bringen suchte, war ein weiterer Schritt auf diesem Wege. Die Vorstellung, der Justiz durch Nachgiebigkeit einen Bereich selbständigen, ungehinderten rechtlichen Wirkens bewahren zu können, erwies sich als Illusion. Die Entwicklung zum Unrecht zieht sich in den Jahren 1933 bis 1940 wie ein roter Faden durch die Tätigkeit des Reichsjustizministeriums und führte nach Gürtner dazu, „daß schließlich das Erreichte beinahe

22 Vgl. VO über die Strafrechtspflege gegen Polen und Juden in den eingegliederten Ostgebieten v. 4.12.41 (RGBl. I, S.759), dazu Werle, Justiz-Strafrecht, S.351 ff., D. Majer, „Fremdvölkische ${ }^{\text {im }}$ im Dritten Reich, Boppard am Rhein 1981, S.744ff., und L. Gruchmann, „Nacht- und Nebel“-Justiz. Die Mitwirkung deutscher Strafgerichte an der Bekämpfung des Widerstandes in den besetzten westeuropäischen Ländern 1942-1944 (VfZ 1981, S. 343 ff.), S. 345 ff. 
ebenso schlimme Züge trug, wie das dadurch Verhütete ${ }^{\text {“23 }}$, bis Thierack ab August 1942 ohne juristische Skrupel daranging, Hitlers Auftrag zu erfüllen und „eine nationalsozialistische Rechtspflege aufzubauen" ${ }^{24}$ Am Anfang dieser Entwicklung stand der verhängnisvolle Irrtum, dem Gürtner und die führenden konservativen Kräfte des Reichsjustizministeriums erlagen: daß das Gedeihen der Nation am besten durch einen autoritären, d.h. antidemokratischen, antiliberalen und antiparlamentarischen Staat gewährleistet werden könne, wie ihn Hitler und die Nationalsozialisten $1933 \mathrm{zu}$ verwirklichen versprachen, und daß zur Erreichung dieses Zieles die Unverbrüchlichkeit des Rechtsstaates „vorübergehend“ mißachtet werden könne, ohne Recht und Gerechtigkeit auf die Dauer zu zerstören.

23 So treffend G. Radbruch, Des Reichsjustizministeriums Ruhm und Ende (SJZ 1948, S. 60).

${ }^{24} \mathrm{Vgl}$. Erlaß des Führers über besondere Vollmachten des Reichsministers der Justiz v. 20.8. 1942 (RGBI. I, S. 535). 